\title{
The microphysics of clouds over the Antarctic Peninsula - Part 2: modelling aspects within Polar WRF
}

\author{
Constantino Listowski ${ }^{1, a}$ and Tom Lachlan-Cope ${ }^{1}$ \\ ${ }^{1}$ British Antarctic Survey, NERC, High Cross, Madingley Rd, Cambridge, CB3 OET, UK \\ ${ }^{a}$ now at: LATMOS/IPSL, UVSQ Université Paris-Saclay, UPMC Univ. Paris 06, CNRS, Guyancourt, France
}

Correspondence to: Constantino Listowski (constantino.listowski@latmos.ipsl.fr)

Received: 19 December 2016 - Discussion started: 19 January 2017

Revised: 20 June 2017 - Accepted: 12 July 2017 - Published: 31 August 2017

\begin{abstract}
The first intercomparisons of cloud microphysics schemes implemented in the Weather Research and Forecasting (WRF) mesoscale atmospheric model (version 3.5.1) are performed on the Antarctic Peninsula using the polar version of WRF (Polar WRF) at $5 \mathrm{~km}$ resolution, along with comparisons to the British Antarctic Survey's aircraft measurements (presented in part 1 of this work; Lachlan-Cope et al., 2016). This study follows previous works suggesting the misrepresentation of the cloud thermodynamic phase in order to explain large radiative biases derived at the surface in Polar WRF continent-wide (at $15 \mathrm{~km}$ or coarser horizontal resolution) and in the Polar WRF-based operational forecast model Antarctic Mesoscale Prediction System (AMPS) over the Larsen C Ice Shelf at $5 \mathrm{~km}$ horizontal resolution. Five cloud microphysics schemes are investigated: the WRF single-moment five-class scheme (WSM5), the WRF doublemoment six-class scheme (WDM6), the Morrison doublemoment scheme, the Thompson scheme, and the MilbrandtYau double-moment seven-class scheme. WSM5 (used in AMPS) and WDM6 (an upgrade version of WSM5) lead to the largest biases in observed supercooled liquid phase and surface radiative biases. The schemes simulating clouds in closest agreement to the observations are the Morrison, Thompson, and Milbrandt schemes for their better average prediction of occurrences of clouds and cloud phase. Interestingly, those three schemes are also the ones allowing for significant reduction of the longwave surface radiative bias over the Larsen C Ice Shelf (eastern side of the peninsula). This is important for surface energy budget consideration with Polar WRF since the cloud radiative effect is more pronounced in the infrared over icy surfaces. Overall, the Morrison scheme compares better to the cloud ob-
\end{abstract}

servation and radiation measurements. The fact that WSM5 and WDM6 are single-moment parameterizations for the ice crystals is responsible for their lesser ability to model the supercooled liquid clouds compared to the other schemes. However, our investigation shows that all the schemes fail at simulating the supercooled liquid mass at some temperatures (altitudes) where observations show evidence of its persistence. An ice nuclei parameterization relying on both temperature and aerosol content like DeMott et al. (2010) (not currently used in WRF cloud schemes) is in best agreement with the observations, at temperatures and aerosol concentration characteristic of the Antarctic Peninsula where the primary ice production occurs (part 1), compared to parameterization only relying on the atmospheric temperature (used by the WRF cloud schemes). Overall, a realistic double-moment ice microphysics implementation is needed for the correct representation of the supercooled liquid phase in Antarctic clouds. Moreover, a more realistic ice-nucleating particle alone is not enough to improve the cloud modelling, and water vapour and temperature biases also need to be further investigated and reduced.

\section{Introduction}

Tropospheric clouds in Antarctica are amongst the least well observed on Earth due to the remote environment and harsh conditions that make field observation difficult. As a result of this, no modelling study has ever focused on comparing the performances of Weather Research and Forecasting (WRF) cloud microphysics schemes to in situ cloud measurements. Yet this is a necessary step to improve our ability to model the 
Antarctic atmosphere. Better understanding the meteorology is also crucial for providing reliable forecast to aircraft or ground operations in the Antarctic.

Much attention has focused on Antarctica's energy budget in recent years, notably due to the West Antarctic Ice Sheet warming (O'Donnell et al., 2011; Bromwich et al., 2013b), and on large ice mass loss (gain) recorded in West (East) Antarctica (Harig and Simons, 2015). In order to assess how atmospherically driven processes affect the evolution of Antarctica's ice mass and surface energy budget, our understanding and modelling of the clouds in that region must be improved. Importantly, changes in microphysical properties of Antarctic clouds impact the atmosphere dynamics at lower southern latitudes and even at northern latitudes, since their altered radiative properties modify the north-south temperature gradient (Lubin et al., 1998).

The Antarctic Peninsula is characterized by high mountains forming a barrier to the dominant westerlies, which roughly extends across the longitudes 67 to $65^{\circ} \mathrm{W}$ at the latitude of Rothera Research Station $\left(67.586^{\circ} \mathrm{S}\right)$, with altitudes up to around $2500 \mathrm{~m}$ in some places. This major topographical feature causes significant differences between each side in terms of temperatures (Morris and Vaughan, 2003), precipitation (King and Turner, 1997), and aerosols and cloud microphysics (as concluded in part 1 of this work; LachlanCope et al., 2016). Significant climate changes have been recently observed across the peninsula during the last few decades (O'Donnell et al., 2011; Turner et al., 2016). Interestingly, oceanically driven mechanisms are the main contributor to glaciers melting on the peninsula (Wouters et al., 2015). In this context, improving the modelling of the different components of the energy budget of the Antarctic Peninsula is required to better understand its climatological evolution and how atmosphere-driven processes act along with ocean-driven processes to impact Antarctica's ice mass balance and temperatures. Clouds are one of the least well understood of the atmospheric components (Boucher et al., 2013; Flato et al., 2013).

Recent studies have pointed towards Antarctic clouds being responsible for large shortwave (SW) and longwave (LW) surface radiative biases (several tens of watts per square metre $\left.\left(\mathrm{W} \mathrm{m}^{-2}\right)\right)$ in high-resolution models over the whole continent (Bromwich et al., 2013a) and, more specifically, over the Larsen C Ice Shelf on the eastern side of the peninsula (King et al., 2015). Improved cloud physics allowing for realistic ice supersaturations led to lower surface energy budget biases in the high-resolution Regional Atmospheric Climate MOdel (RACMO2; van Wessem et al., 2014). King et al. (2015) compared three mesoscale models simulations over the Larsen $\mathrm{C}$ Ice Shelf during a summer month and showed how they differed in the amount of cloud liquid and cloud ice that were simulated. The authors suggested that this explained the comparatively different surface biases, and they pointed towards issues in modelling the thermodynamic phase of clouds and, more specifically, the supercooled liquid component (liquid maintained at $T \leq 0{ }^{\circ} \mathrm{C}$ ). The modelling of the mixed-phase clouds needs to be improved in models, and the misrepresentation (underestimation) of supercooled liquid over Antarctica can be related to its poor representation over the surrounding Southern Ocean as a whole (Lawson and Gettelman, 2014).

A related issue deals with the initiation of the ice phase in clouds, which is driven by the ice-nucleating particles (INPs). They are the substrates needed to activate ice crystal growth either directly from the vapour condensing on the INPs (deposition freezing) or from the freezing of supercooled droplets following immersion of, contact with, or condensation on an INP (Hoose and Möhler, 2012). In the condensation case the INPs act as cloud condensation nuclei $(\mathrm{CCN})$ first to form a droplet. Homogeneous freezing of droplets (i.e. without the intervention of an INP) can occur at temperatures usually believed to be colder than $-38^{\circ}$ (Hoose and Möhler, 2012), although there are possible significant effects already below $-30^{\circ}$ (Herbert et al., 2015). In a remote place like Antarctica little is known about the exact nature of the INPs, although studies have been identifying various plausible sources: biological sources from the snowy surface, blowing snow, sulfate particles resulting from sea-surface emissions, and mineral dust lifted from ice-free regions or brought by winds from continental landmasses at lower latitudes (e.g. South America). Many candidates are found in the literature to explain the presence of INPs in Antarctica (see Bromwich et al., 2012, for a review). Similar questions arise for INPs in marine air in remote places like in the middle of the Southern Ocean (Burrows et al., 2013), which surrounds the Antarctic continent. Regarding CCN, which are needed to activate cloud droplet growth, sea salt is known to be an efficient substrate. Interestingly, its emission in the polar region's boundary layer is believed to be enhanced in places where brine-rich snow covering sea ice can be lifted by the winds (Yang et al., 2008).

In the last decades, very localized ground measurements using in situ or remote-sensing techniques have allowed characterizing microphysical properties of clouds (particle phase, particle size, crystals shape); however these observations are sparse (Lachlan-Cope, 2010; Grosvenor et al., 2012). Ground-based remote-sensing measurements provide local continuous measurements making it possible to link clouds properties to precipitation or accumulation events (Gorodetskaya et al., 2015).

Two aircraft campaigns led by the British Antarctic Survey (BAS) took place during summer 2010 and 2011, measuring cloud properties on both sides of the Antarctic Peninsula (Lachlan-Cope et al., 2016; hereafter referred to as part 1). Analysis of some of the 2010 flights was already presented in Grosvenor et al. (2012) with a focus on cloud ice and secondary ice multiplication processes. These two campaigns and the surface radiative biases pointing towards a misrepresentation of Antarctic clouds within high-resolution models at $5 \mathrm{~km}$ resolution (King et al., 2015) or at coarser resolu- 
tion (Bromwich et al., 2013a) motivate this first attempt to compare some of the existing cloud microphysics schemes implemented in the WRF v3.5.1 atmospheric model (Skamarock et al., 2008), with simulations performed at $5 \mathrm{~km}$ resolution. We use the polar version of WRF (Polar WRF; Hines and Bromwich, 2008), which has optimised representation for polar regions in terms of surface properties (ice, snow, sea ice, and seawater) and processes (heat transfer between the surface and the atmosphere). Polar WRF is widely used by the Antarctic community, and it is used by the Antarctic Mesoscale Prediction System (AMPS; Powers et al., 2012), which is an operational forecast model that provides support for international Antarctic efforts. Bromwich et al. (2013a) and King et al. (2015) relied on Polar WRF and AMPS, respectively, in their study.

In Sect. 2 we present the model settings along with the microphysics schemes used in this work and explain their main characteristics. In Sect. 3 we discuss simple results of radiation biases to illustrate the importance of cloud schemes on the peninsula's energy budget. In Sect. 4 we compare modelling results to in situ measurements already presented in part 1 and evaluate the performance of the cloud microphysics schemes. In Sect. 5 we comment on the performances of the cloud schemes investigated, discuss sensitivity issues of the present study, and comment on the aspects to consider in future work for improving cloud microphysics parameterizations in Antarctica. In Sect. 6 the main aspects of this work are summarized.

\section{Observations, atmospheric model, and the cloud microphysics schemes}

\subsection{Overview of the airborne observations}

Two campaigns of in situ cloud measurements took place on both sides of the Antarctic Peninsula $\left(61-73^{\circ} \mathrm{W}\right)$ in February 2010 and January 2011 (part 1). The observations were made with the British Antarctic Survey's instrumented Twin Otter aircraft (King et al., 2008) based at Rothera Research Station $\left(67.586^{\circ} \mathrm{S}, 68.133^{\circ} \mathrm{W}\right)$. ERA-Interim reanalysis shows an intensified northerly flow in 2011 to the west of the peninsula, expected to bring warmer air. However colder temperatures were observed in the reanalysis, in the radiosonde ascents made at Rothera (not shown), and in the aircraft measurements (a tendency correctly reproduced in the simulations; see Sect. 4.4). This can be explained by colder air being pulled from the Weddell Sea (to the east of the peninsula) during the 2011 campaign, following intensification and eastward movement of the Amundsen Sea Low to the west of the peninsula (part 1, their Fig. 3). Results on average cloud properties (predominantly stratus or altostratus) comparing both campaigns and both sides of the peninsula are presented in part 1, and detailed results on some 2010 flights are presented in Grosvenor et al. (2012). The aircraft was fit- ted with various instruments measuring notably temperature, pressure, humidity, turbulence, and radiation as well as with a Droplet Measurement Technologies Cloud, Aerosol, and Precipitating Spectrometer (CAPS) (Baumgardner et al., 2001). The CAPS has a Cloud and Aerosol Spectrometer (CAS), a Cloud Imaging Probe (CIP), and a hotwire liquid water content (LWC) sensor. The CAS measures particle size (diameter) between 0.5 and $50 \mu \mathrm{m}$, and the hotwire was used to validate the supercooled LWC as derived from the CAS, which cannot discriminate between liquid and ice. Also, the CAS showed a distinct peak in the size distribution in the range $8-12 \mu \mathrm{m}$ (in diameter) indicative of drop formations. The CIP images particles with sizes between $25 \mu \mathrm{m}$ and $1.5 \mathrm{~mm}$, with $25 \mu \mathrm{m}$ pixel resolution. Particles smaller than $200 \mu \mathrm{m}$ in size cannot be discriminated between crystals and droplets. Their number concentration is very small compared to the CAS, and therefore they were ignored (see also Sect. 4.3.1 of this paper for the impact on the LWC). The ice water content (IWC) was calculated using the Brown and Francis mass-dimension parameterization (Brown and Francis, 1995). More details on data processing and the derivation of the ice crystal number concentration are given in part $1 . \mathrm{Fi}$ nally, the CIP samples at a rate of a little less than $10 \mathrm{~L} \mathrm{~s}^{-1}$, hence the lower limit for the measured crystal number concentration of a little more than $0.1 \mathrm{~L}^{-1}$.

\subsection{Model settings}

Polar WRF v3.5.1 was used with a downscaling method (Fig. 1a) where a $45 \mathrm{~km}$ resolution domain contains a smaller $15 \mathrm{~km}$ resolution nest, which itself contains a smaller nest at $5 \mathrm{~km}$ resolution centred over the regions where the 2010 and 2011 flights took place (Fig. 1b). The topography is from Fretwell et al. (2013). The simulation outputs of the highest-resolution domain were used for the present analysis. We work at a similar horizontal resolution to King et al. (2015) $(5 \mathrm{~km})$ and at a higher resolution than Bromwich et al. (2013a) (60 and $15 \mathrm{~km}$ ). Both studies pointed towards the clouds being responsible for the surface radiative biases measured, but they did not investigate the actual effect of using a different cloud microphysics schemes.

The simulation is one way, in the sense that no information is passed in return from one domain to its parent domain. Table 1 summarizes the WRF settings used for the main physical processes, except for the cloud microphysics schemes, which are addressed in Sect. 2.3. King et al. (2015) (hereafter referred to as $\mathrm{K} 15$ ) were interested in the surface radiative biases on the Larsen $\mathrm{C}$ Ice Shelf on the eastern side of the peninsula. They used outputs from AMPS (built on Polar WRF v3.0.1 for the 2011 period). For consistency we use the same shortwave- and longwave-radiation schemes as in K15 (Table 1). More generally we are using the set of WRF physics parameterization used by the operational model AMPS, which should be a relevant framework to testing the cloud microphysics schemes in Antarctica. Regard- 

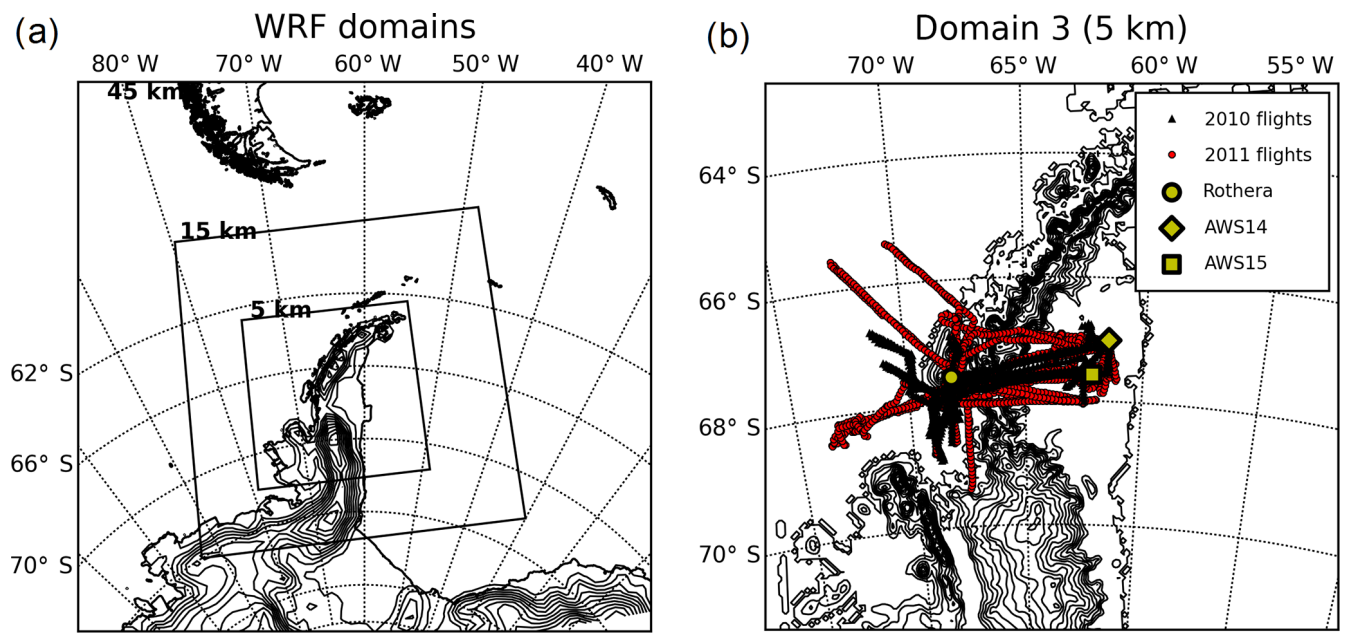

Figure 1. (a) WRF configurations for the three domains used for all simulations and (b) close-up on the highest-resolution domain with detailed topography from Fretwell et al. (2013). The black triangles indicate the flight tracks of the 2010 campaign, while the red circles indicate the flight tracks of the 2011 campaign. The other markers indicate Rothera Research Station (circle) and the automatic weather stations (AWSs) 14 (diamond) and 15 (square) located on the Larsen C Ice Shelf.

Table 1. WRF settings used for the simulations. The number in parentheses indicates the scheme number (option) in the WRF settings.

\begin{tabular}{ll}
\hline Setting & Value \\
\hline Number of domains & 3 \\
Domains size $(\mathrm{px})$ & $80 / 130 / 208$ \\
Resolution $(\mathrm{km})$ & $45 / 15 / 5$ \\
Number of vertical levels & 30 \\
Top pressure $(\mathrm{hPa})$ & 50 \\
Time step (s) & $180 / 60 / 20$ \\
Cumulus param. & on/on/off \\
LW radiation scheme & $\mathrm{RRTM}^{*}(1)$ \\
SW radiation scheme & Goddard (2) \\
Surface atmospheric layer & Eta similarity (2) \\
Land surface physics & Noah Land Surface Model (2) \\
Planetary boundary layer & Mellor-Yamada-Janjic (2) \\
\hline
\end{tabular}

* Rapid Radiative Transfer Model.

ing the boundary layer parameterization, Deb et al. (2016) showed that Polar WRF performances at the surface are most sensitive to the choice of the planetary boundary layer scheme and that the Mellor-Yamada-Janjic (MYJ) scheme is the best performer in terms of the temperature diurnal cycle (in West Antarctica) at $5 \mathrm{~km}$ resolution, and it is the one used in AMPS and in our study.

One of the main differences with K15 is that our simulation is constrained horizontally and vertically, at the boundaries of the $45 \mathrm{~km}$ resolution domain, with ERA-Interim reanalysis data instead of Global Forecast System data (GFS, run by the US National Centers for Environmental Prediction). ERA-Interim is the latest global atmospheric reanal- ysis (Dee et al., 2011) provided by the European Centre for Medium-Range Weather Forecasts (ECMWF). This reanalysis is based on archived observations from 1989 onward. It is obtained through data assimilation into an atmospheric model running at a resolution of $0.75 \times 0.75^{\circ}$, which roughly corresponds to $30 \mathrm{~km}$ in longitude by $80 \mathrm{~km}$ in latitude, at the latitude of Rothera Research Station $\left(67.586^{\circ} \mathrm{S}\right)$. Bromwich et al. (2013a) showed that using ERA-Interim reanalysis for initial and boundary conditions produces the best skills within Polar WRF.

We ran two sets of simulations. The first set spans the period 1 February 2010 to 5 March 2010, and the second set goes from 1 January 2011 to 11 February 2011 (the first two days were not included in the analysis as part of the model spin-up). These two periods cover the time of the two aircraft campaigns, including the period during 2011 when a camp was set up on the Larsen C Ice Shelf, close to automatic weather station 14 (AWS14; see Fig. 1b), as described in $\mathrm{K} 15$.

\subsection{Cloud microphysics schemes}

We used five different microphysics scheme to assess their ability to model realistic clouds across the Antarctic Peninsula. None of the WRF microphysics schemes has been specifically developed for modelling Antarctic clouds. As no work has been done so far on comparing microphysics schemes implemented in Polar WRF with respect to their performances for Antarctic clouds, we used them as such with no modification. This appeared to be the most reasonable first step that can then help guide further development of Antarctic clouds microphysics modelling. 
Table 2. Microphysics schemes of WRF (version 3.5.1) used in this work with their predicted cloud variables. DM stands for double-moment scheme (see text for details). All prognosed hydrometeor variables are designated by letters as follows. c: clouds droplets; i: ice crystals; r: rain drops; s: snow crystals; g: graupel; h: hail. The Morrison scheme can be used as a double-moment scheme for droplets only when WRF is used with WRF-Chem. See text for the references related to the cloud microphysics schemes.

\begin{tabular}{llll}
\hline Scheme & Mass & Number & Comment \\
\hline WSM5 & $\mathrm{c}, \mathrm{r}, \mathrm{i}, \mathrm{s}$ & - & Used in the Antarctic Mesoscale Prediction System (AMPS) \\
WDM6 & $\mathrm{c}, \mathrm{r}, \mathrm{i}, \mathrm{s}, \mathrm{g}$ & $\mathrm{c}, \mathrm{r}$ & Upgrade of WSM5 to DM for c, r and predicted CCN \\
Morrison & $\mathrm{c}, \mathrm{r}, \mathrm{i}, \mathrm{s}, \mathrm{g}$ & $\mathrm{r}, \mathrm{i}, \mathrm{s}, \mathrm{g}$ & Used in the Arctic System Reanalysis (ASR) \\
Thompson & $\mathrm{c}, \mathrm{r}, \mathrm{i}, \mathrm{s}, \mathrm{g}$ & $\mathrm{r}, \mathrm{i}$ & State-of-the-art parameterization of snow \\
Milbrandt & $\mathrm{c}, \mathrm{r}, \mathrm{i}, \mathrm{s}, \mathrm{g}, \mathrm{h}$ & $\mathrm{c}, \mathrm{r}, \mathrm{i}, \mathrm{s}, \mathrm{g}, \mathrm{h}$ & DM for all hydrometeors and predicted CCN \\
\hline
\end{tabular}

Generally speaking, each scheme is a bulk microphysics parameterization (BMP) where either mass (single-moment - SM - scheme) or both mass and number density (doublemoment - DM - scheme) of the various types of hydrometeors are independently predicted. In the DM case, the scheme allows for a more realistic behaviour of clouds. Indeed, predicting both the mass and the number density of hydrometeors allows the average particle size to be predicted, which in turn allows the modelling of all size-dependent processes like sedimentation, accretion, and growth to be improved (Igel et al., 2015). All schemes have non-precipitable and precipitable hydrometeors. The former (cloud droplets, ice crystals) are considered as having zero sedimentation velocity in the collection or accretion processes, in contrast to the latter (rain drops, snow crystals, graupel, or hail), which act as collector particles. Finally, we did not use any microphysics radius bin model (as opposed to the BMPs). They predict the evolution of cloud particles within given size bins and allow for the prediction of the actual particle size distributions. Bin models are missing from WRF v3.5.1. However, a bin model is more demanding in terms of computer time, and BMPs are used in current global or regional atmospheric models and in operational forecast models like AMPS. Table 2 highlights some aspects of the cloud microphysics schemes investigated in this study.

The actual default microphysics scheme of WRF is WRF single moment 3 (WSM3), which has been discarded here because it does not allow for the existence of supercooled liquid droplets. Thus, our default reference scheme is the WRF single moment 5 (WSM5), which allows for mixed-phase cloud formation (Hong et al., 2004). WSM5 is a SM scheme for all the hydrometeors. It is used in the operational model AMPS.

The WRF double-moment 6 (WDM6; Lim and Hong, 2010) is an improvement on WSM5, in which droplets and rain are both treated with DM schemes, graupel is included, and all the ice phase particles are treated with a SM scheme. It is used here in order to test the improvement of the prediction of the supercooled liquid phase that one could expect from the use of a more sophisticated parameterization for the liquid phase (DM instead of SM as in WSM5).
The Morrison scheme (Morrison et al., 2005, 2009) is a full DM scheme for all icy hydrometeors and rain, and SM for water droplets. The Morrison scheme requires the coupling to the WRF-Chem module (Peckham et al., 2011) in order to act as a DM scheme for the cloud droplets; since such coupling was not available, we used the Morrison scheme as a SM scheme for the water droplets. This scheme is used in the Arctic System Reanalysis (ASR), which is based on Polar WRF as well. It slightly improved the modelling of the clouds in the northern polar summer compared to WSM5 at $30 \mathrm{~km}$ resolution (Wesslén et al., 2014), and this paper investigates its ability to better represent the clouds in the southern polar region.

The Thompson scheme (Thompson et al., 2008) has a state-of-the art parameterization of snow, which relies on extensive flight measurements, and it uses a more realistic sizedependent density for snow particles. The latter are treated as non-spherical, and their density decreases with increasing size. This was identified as having a major influence on the production of supercooled drops mainly because of a decreased efficiency in the riming process resulting in longerlasting supercooled drops (Thompson et al., 2008).

Finally, The Milbrandt-Yau scheme (Milbrandt and Yau, 2005a, b) (hereafter designated as Milbrandt) is a full doublemoment scheme (with the shape parameters of the particle distribution being fixed). It is used here in order to test the ability of a full double-moment scheme to predict supercooled drops better than the Morrison or the Thompson schemes.

Table 3 details the way the cloud schemes treat the initiation of the cloud ice phase and the cloud liquid. The initiation of the ice phase is the most complex part, and it relies on INP parameterizations. They diagnose the number of INPs, and hence the number of activated crystals, accounting for the various freezing modes described in the introduction. The INP parameterizations rely on the atmospheric temperature only. They are used in various ways by the different cloud microphysics schemes as illustrated in Table 3. They deal with primary ice production (droplets or vapour converted to ice through interaction with INPs), as opposed to secondary ice processes, which result from the interaction 
Table 3. Characteristics of the ice phase and liquid phase activation for the microphysics schemes. $T$ refers to the atmospheric temperature, and qc to the liquid water content. $S_{\mathrm{i}}\left(S_{\mathrm{W}}\right)$ is the saturation ratio with respect to ice (liquid water). $r_{\text {ice/snow }}$ indicate the cut-off size for icy particles considered either as ice crystals (smaller particles) or snow (larger particles). INP parameterizations (INP param.) account for the various freezing processes presented in Sect. 1: imm is immersion freezing; dep is deposition freezing; cont is contact freezing: cond is condensation freezing; and hom is homogeneous freezing (considered as instantaneous, i.e. straight conversion of liquid to ice). IN/freezing parameterizations' references: (Fmod) is a modified version of Fletcher (1962) presented in Hong et al. (2004); (C) is Cooper (1986); (M) is Meyers et al. (1992) Eq. (2.4); ( $\left.\mathbf{M}^{\prime}\right)$ is Meyers et al. (1992) Eq. (2.6); (B) is Bigg (1953) for probabilistic freezing; (DeM) is Demott et al. (1994) for probabilistic freezing. CCN activation parameterizations: (K) is Khairoutdinov and Kogan (2000); (CP) is Cohard and Pinty (2000).

\begin{tabular}{|c|c|c|c|c|}
\hline Scheme & Triggering of ice formation & INP param. & $r_{\text {ice/snow }}$ & Droplets/CCN \\
\hline WSM5 & $\begin{array}{l}S_{\mathrm{i}}>1 \\
{\left[T<0{ }^{\circ} \mathrm{C} \& \mathrm{qc}>0\right]} \\
{\left[T>-40^{\circ} \mathrm{C} \& \mathrm{qc}>0\right]}\end{array}$ & $\begin{array}{l}\text { (Fmod) dep } \\
\text { (B) imm } \\
\text { hom }\end{array}$ & $250 \mu \mathrm{m}$ & $300 \mathrm{~cm}^{-3}$ \\
\hline WDM6 & Same as WSM5 & & & $\mathrm{CCN}(\mathrm{K})$ \\
\hline Morrison & $\begin{array}{l}{\left[T>-8^{\circ} \mathrm{C} \& S_{\mathrm{W}}>0.999\right] \text { or }\left[S_{\mathrm{i}}>1.08\right]} \\
{\left[T>-4^{\circ} \mathrm{C} \& \mathrm{qc}>0\right]} \\
{\left[T>-40^{\circ} \mathrm{C} \& \mathrm{qc}>0\right]}\end{array}$ & $\begin{array}{l}\text { (C) dep, cond } \\
\left(\mathrm{M}^{\prime}\right) \text { cont }+(\mathrm{B}) \mathrm{imm} \\
\text { hom }\end{array}$ & $125 \mu \mathrm{m}$ & $250 \mathrm{~cm}^{-3}$ \\
\hline Thompson & $\begin{array}{l}{\left[T>-12^{\circ} \mathrm{C} \& S_{\mathrm{W}}>1 .\right] \text { or }\left[S_{\mathrm{i}}>1.25\right]} \\
{\left[T>0{ }^{\circ} \mathrm{C} \& \mathrm{qc}>0\right]} \\
{\left[T>-38^{\circ} \mathrm{C} \& \mathrm{qc}>0\right]}\end{array}$ & $\begin{array}{l}\text { (C) dep, cond } \\
\text { (B) imm } \\
\text { hom }\end{array}$ & $200 \mu \mathrm{m}$ & $100 \mathrm{~cm}^{-3}$ \\
\hline Milbrandt & $\begin{array}{l}{\left[T>-5^{\circ} \mathrm{C} \& S_{\mathrm{i}}>1\right]} \\
{\left[T>-2^{\circ} \mathrm{C} \& \mathrm{qc}>0\right]} \\
{\left[T>-30^{\circ} \mathrm{C} \& \mathrm{qc}>0\right]} \\
{\left[T>-50^{\circ} \mathrm{C} \& \mathrm{qc}>0\right]}\end{array}$ & $\begin{array}{l}\text { (M) dep, cond } \\
\left(\mathrm{M}^{\prime}\right) \text { cont } \\
\text { (DeM) hom } \\
\text { hom }\end{array}$ & $100 \mu \mathrm{m}$ & $\mathrm{CCN}(\mathrm{CP})$ \\
\hline
\end{tabular}

of already-formed crystals with other crystals or with supercooled droplets. Finally, the liquid phase relies on a fixed number of droplets or a predicted number of activated $\mathrm{CCN}$ (hence number of drops), depending on the cloud scheme. At each time step, the liquid phase is formed after the ice microphysics is computed provided there is still an excess of vapour compared to equilibrium (i.e. if $S_{\mathrm{w}}>1$, where $S_{\mathrm{w}}$ is the saturation ratio with respect to liquid water).

\section{Preliminaries: results in radiation biases}

Large biases in both surface downward shortwave (SW, solar flux) and longwave (LW) radiation were reported east of the peninsula over the Larsen C Ice Shelf by K15. The authors compared the summertime surface energy budget as simulated for January 2011 by three mesoscale models: AMPS, the UK Met Office Unified Model (UM) (see Wilson and Ballard, 1999, for the cloud scheme), and RACMO2 version 2.3 (see van Wessem et al., 2014, for the cloud scheme). A field camp was established close to AWS14 (see Fig. 1b) where radiosonde ascents allowed the water vapour column density to be calculated. AWS14 is fitted with SW and LW radiometers. K15 showed that all models mostly overestimated SW radiation by several tens of watts per square metre $\left(\mathrm{W} \mathrm{m}^{-2}\right.$, positive bias), while they underestimated LW radiation (negative bias). They pointed towards the lack of simulated clouds that blocked the incoming shortwave solar radiation and emitted thermal radiation back to the surface. The only exception was noted for the UM, which had several tens of watts per square metre $\left(\mathrm{W} \mathrm{m}^{-2}\right)$ of negative bias in $\mathrm{SW}$, suggesting an overestimation of the cloud cover. AMPS simulated clouds predominantly composed of ice with very little or even zero liquid water, during this period over AWS14, providing an explanation to the very large surface radiative biases, especially in SW to which small droplets are the most responsive. Ice clouds, however, were simulated, and K15 pointed towards a misrepresentation of the actual phase of the clouds to explain the biases observed.

Following K15, Table 4 shows average biases of daily averaged surface downward SW and LW fluxes. They were derived by subtracting the observed value to the modelled value. Three sites were selected: the British Antarctic Survey's Rothera Research Station, on the western side of the Antarctic Peninsula, and two automatic weather stations AWS14 and AWS15 - on the eastern side of the peninsula on the Larsen C Ice Shelf (see Fig. 1b). Both AWSs are about $70 \mathrm{~km}$ apart on the ice shelf. Table 4 also indicates whether the difference between WSM5 (used in AMPS) and the other schemes is statistically significant (with a Student's $t$ test). 
Table 4. Monthly averaged shortwave (SW) and longwave (LW) surface radiative biases of daily averaged biases over Rothera, AWS14, and AWS15 for the two time periods of interest. The exponent gives the standard deviation (SD) of the daily biases. The number of " $x$ " symbols as subscript tells how significant the difference is between WSM5 and each of the other three schemes (one, two, or three "x"s means statistical significance at the 90,95 , or $99 \%$ level, respectively). No symbol means that the difference is not significant. Statistically significant reductions in SW/LW biases are emphasized with bold characters.

\begin{tabular}{|c|c|c|c|c|c|c|c|}
\hline \multirow{2}{*}{$\begin{array}{l}\text { Radiation } \\
\text { bias }\end{array}$} & \multirow{2}{*}{$\begin{array}{l}\text { Microphysics } \\
\text { scheme }\end{array}$} & \multicolumn{2}{|c|}{ Rothera } & \multicolumn{2}{|c|}{ AWS 14} & \multicolumn{2}{|c|}{ AWS 15} \\
\hline & & 2010 & 2011 & 2010 & 2011 & 2010 & 2011 \\
\hline $\begin{array}{l}\mathrm{SW}^{\mathrm{SD}} \\
\left(\mathrm{W} \mathrm{m}^{-2}\right)\end{array}$ & $\begin{array}{l}\text { WSM5 } \\
\text { Morrison } \\
\text { Thompson } \\
\text { Milbrandt }\end{array}$ & $\begin{array}{r}15^{68} \\
20^{63} \\
46_{x x}^{67} \\
7^{63}\end{array}$ & $\begin{array}{l}49^{76} \\
52^{84} \\
70^{89} \\
48^{82}\end{array}$ & $\begin{array}{l}-28^{61} \\
-51_{x}^{60} \\
-24^{62} \\
-33^{62}\end{array}$ & $\begin{array}{c}53^{52} \\
-5_{\mathrm{xxx}}^{61} \\
37^{52} \\
\mathbf{3 1}_{\mathrm{x}}^{56}\end{array}$ & $\begin{array}{l}-22^{52} \\
-43_{x}^{52} \\
-24^{51} \\
-30^{50}\end{array}$ & $\begin{array}{r}48^{51} \\
-\mathbf{1} 2_{\mathrm{xxx}}^{50} \\
29_{\mathrm{X}}^{50} \\
\mathbf{2 8}_{\mathrm{X}}^{53}\end{array}$ \\
\hline $\begin{array}{l}\mathrm{LW}^{\mathrm{SD}} \\
\left(\mathrm{W} \mathrm{m}^{-2}\right)\end{array}$ & $\begin{array}{l}\text { WSM5 } \\
\text { Morrison } \\
\text { Thompson } \\
\text { Milbrandt }\end{array}$ & $\begin{array}{l}-28^{25} \\
-22^{22} \\
-24^{26} \\
-\mathbf{1 9}_{\mathrm{X}}^{20}\end{array}$ & $\begin{array}{l}-26^{26} \\
-22^{26} \\
-25^{27} \\
-19^{23}\end{array}$ & $\begin{array}{r}-11^{28} \\
2_{\mathrm{xx}}^{25} \\
\mathbf{0 . 5}_{\mathrm{x}}^{26} \\
\mathbf{3}_{\mathrm{xx}}^{26}\end{array}$ & $\begin{array}{r}-20^{23} \\
\mathbf{1}_{\mathrm{Xxx}}^{21} \\
-\mathbf{6}_{\mathrm{xxx}}^{21} \\
-\mathbf{6}_{\mathrm{xxx}}^{20}\end{array}$ & $\begin{array}{r}-10^{29} \\
\mathbf{4}_{\mathrm{xx}}^{21} \\
\mathbf{3}_{\mathrm{xx}}^{25} \\
\mathbf{5}_{\mathrm{xx}}^{24}\end{array}$ & $\begin{array}{r}-22^{20} \\
\mathbf{1}_{\mathrm{Xxx}}^{19} \\
-9_{\mathrm{Xxx}}^{22} \\
-\mathbf{9}_{\mathrm{Xx}}^{25}\end{array}$ \\
\hline
\end{tabular}

\subsection{The particular case of AWS14 in January 2011}

We first compare results obtained by K15 with the AMPS model over the period 8 January 2011 to 8 February 2011 at AWS14 (see their Table 3) to our results obtained with the WSM5 scheme over the same period (Table 4, fourth column of results). Their computed biases are 56 and $-10 \mathrm{~W} \mathrm{~m}^{-2}$ in SW and LW, respectively. Ours are 53 and $-20 \mathrm{~W} \mathrm{~m}^{-2}$, respectively. Discrepancies in biases can result from the combination of different settings in the AMPS (forcing, number of vertical levels, domain boundaries). However, we do obtain the same orders of magnitude and same signs of biases as K15, consistent with a lack of clouds. A striking result is that the Morrison scheme reduces the biases in both SW and LW in a statistically significant way at the $99 \%$ level, while the Milbrandt and Thompson schemes reduce it significantly in LW only.

Figure 2 (bottom) shows the cloud liquid mass integrated over the entire atmospheric column $\left(\mathrm{kg} \mathrm{m}^{-2}\right)$ for the different simulations as a function of time in the model grid box corresponding to the AWS14 location in 2011. Figure 2 (top) shows the simulated column density of water vapour compared to the radiosonde ascent measurements from the field camp at AWS14 (presented in K15 and plotted in their Fig. 7). The modelled water vapour is consistent with observations in terms of trend and value (within $\pm 1 \mathrm{~kg} \mathrm{~m}^{-2}$ ) between day 8 and day 32. The simulations give similar values within $\pm 1 \mathrm{~kg} \mathrm{~m}^{-2}$ except between day 15 and day 22 (where no observation is available), and all the simulations capture the sharp increase by $6 \mathrm{~kg} \mathrm{~m}^{-2}$ measured around day 28 . Using the Morrison scheme, 2-4 times more liquid cloud mass is simulated than when using the WSM5 scheme (Fig. 2 bottom). The Milbrandt and Thompson schemes lead to intermediate amounts between WSM5 and Morrison, and WDM6 is similar to WSM5. The larger amount of liquid clouds simulated with the Morrison scheme compared to WSM5 is con- sistent with its smaller SW and LW biases at AWS14 in 2011 (Table 4). This is also in line with K15's conclusion that the thermodynamic phase of the clouds was responsible for the SW and LW biases they found in AMPS over the Larsen C Ice Shelf. The Thompson and Milbrandt schemes do have lower SW biases than WSM5 as well; however the improvement is smaller than with the Morrison scheme and less (or not) statistically significant. However, it is still significant for $\mathrm{LW}$ radiation.

The total ice mass is similar from one scheme to another, as shown by Fig. 3 (top). However an important difference arises when considering the cloud ice crystals mass only (i.e. the pristine ice - ignoring the main precipitable particles like snow and graupel particles); WSM5 and WDM6 simulate 34 times more ice crystal mass than the other schemes (Fig. 3, bottom). The Milbrandt scheme leads only occasionally to as much ice mass as WSM5 and WDM6, around 19, 25, and 30 January. Graupel is mainly absent except when using the Milbrandt schemes, which leads to low amounts around $0.05 \mathrm{~kg} \mathrm{~m}^{-2}$ on rare occasions (not shown). Overall, the main difference in the cloud microphysics between the various simulations at AWS14 is the ability of the cloud schemes to sustain supercooled liquid drops, which in turn can explain differences in the SW and LW surface biases. The other difference lies in the distribution of the mass within the total ice phase between cloud ice crystals and snow particles.

\subsection{General results in radiation biases}

For the eastern side of the peninsula (AWS14 and AWS15), the biases shown in Table 4 (right part) demonstrate the importance of the choice of the microphysics scheme for the surface energy budget of the Larsen C Ice Shelf in Polar WRF. Similar biases (sign and order of magnitude) are observed at a given year and for a given scheme between AWS14 and AWS15. This is consistent with the stations be- 

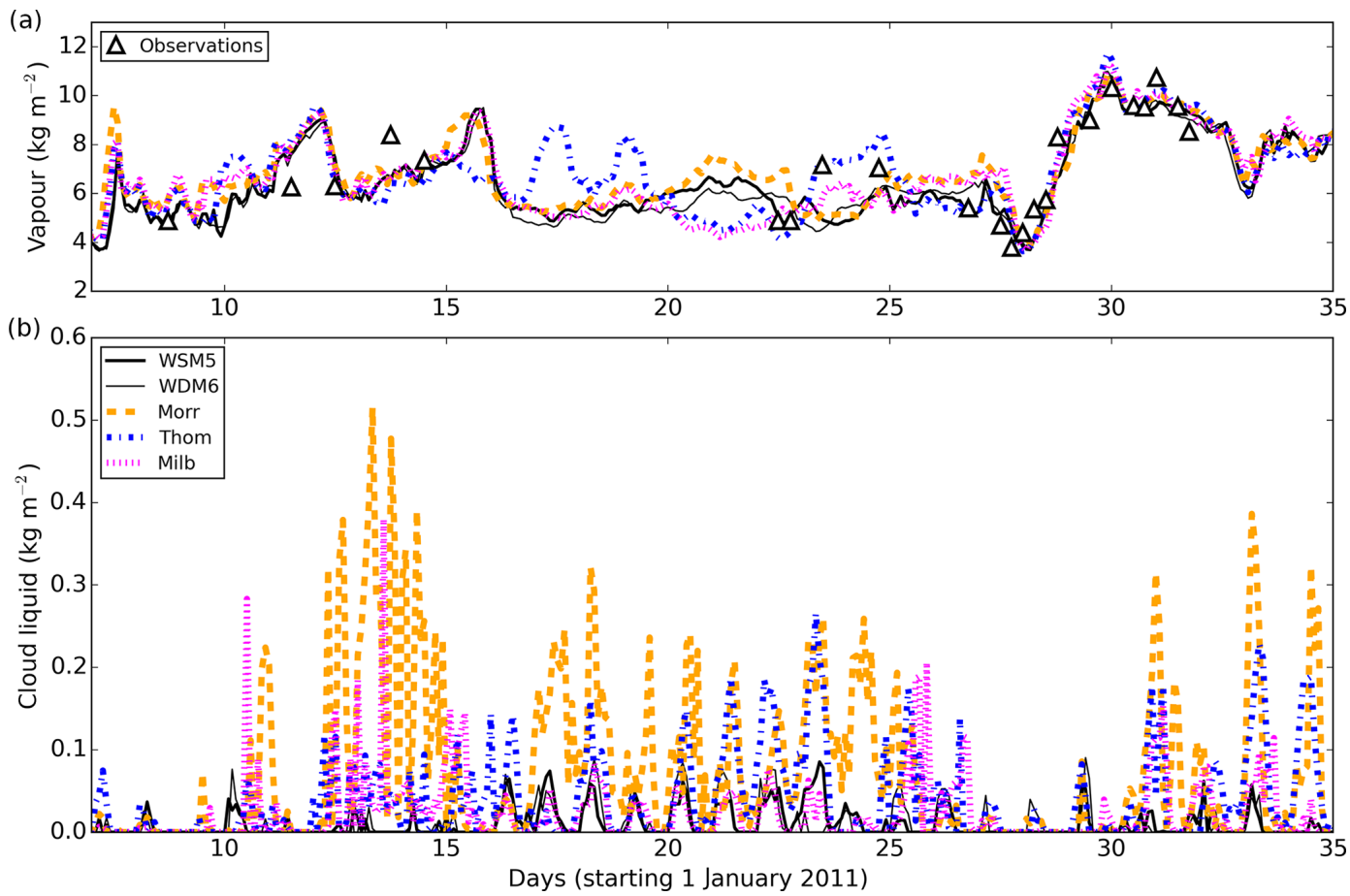

Figure 2. (a) Time series of column density of water vapour $\left(\mathrm{kg} \mathrm{m}^{-2}\right)$ for the different simulations computed in the model grid box corresponding to the AWS14 location in 2011, along with the radiosonde measurements from the field camp (described in K15; see their Fig. 7). (b) Time series of the column density of the cloud liquid $\left(\mathrm{kg} \mathrm{m}^{-2}\right)$ for the different simulations.

(a)
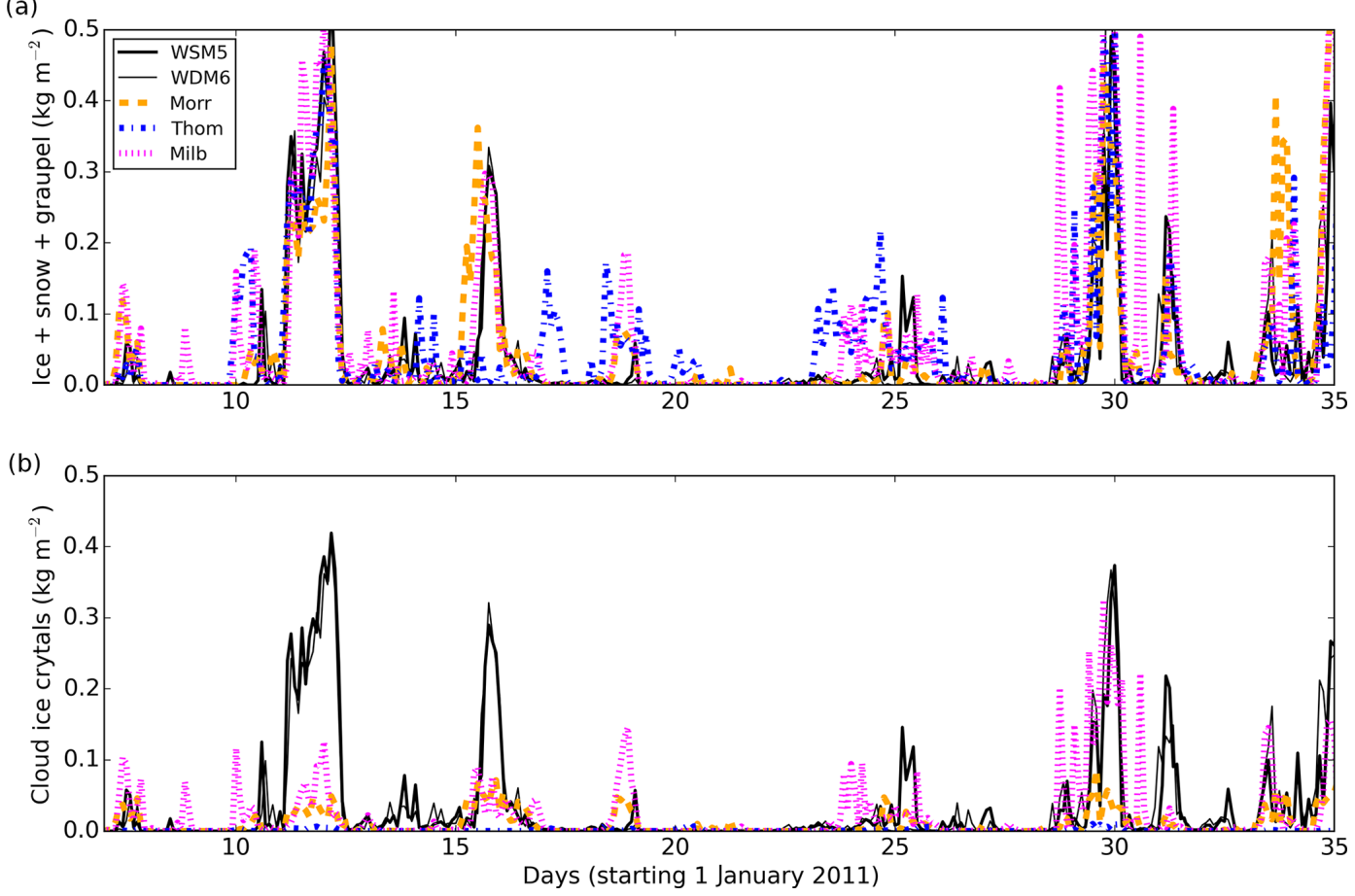

Figure 3. (a) Same as Fig. 2 but for the total ice phase (ice, snow, and graupel particles). (b) Same as Fig. 2 but for cloud ice particles only. 
ing $70 \mathrm{~km}$ apart from each other on the ice shelf, which consists of a relatively flat surface covered with snow and where the large-scale influences are likely to be similar in the absence of significant local variations in the topography or the nature of the surface. A remarkable result is that the LW bias is significantly reduced during both periods of interest on the Larsen C Ice Shelf using the Morrison, Thompson, or Milbrandt schemes compared to WSM5 (or WDM6 - not shown) as can be seen from the lower right part of Table 4. However, the Thompson and the Milbrandt schemes still have a negative LW bias, while Morrison's is slightly positive and gives on average the smallest LW bias at both AWS stations for both years. The standard deviation of daily averaged measurements remains high, but statistical tests show that the differences between WSM5 and the three other schemes are significant, mainly at the $99 \%$ level in 2011 and mainly at the $95 \%$ level in 2010 . The SW bias is significantly reduced only with the Morrison scheme in 2011. However no improvement occurs in 2010 for the SW bias. The Milbrandt and Thompson schemes' SW biases are slightly lower in 2011 with differences to WSM5 that are significant at the $90 \%$ level. In 2010 all the schemes have a large negative SW bias, with the largest amplitude attributed to the Morrison scheme.

For the western side of the peninsula (Rothera Research Station), SW biases are always positive, and LW biases always negative, whatever the cloud scheme or the year considered (left part of Table 4). All simulations consistently show this imbalance, suggesting no improvement in cloud simulation. Furthermore, no statistically significant difference is observed between WSM5 and the other schemes. Note that almost no cloud liquid water (not shown) is simulated above Rothera (as opposed to AWS14, Fig. 2), whatever the cloud scheme used, in line with the persistent large SW and LW biases. Ice and snow (graupel), however, are formed in similar amounts to the ones shown in Fig. 3 (not shown). Overall, Table 4 demonstrates the high sensitivity of the simulated downward radiation fluxes to the microphysics scheme used in Polar WRF.

A major issue in assessing the performances of the cloud microphysics schemes by investigating radiation biases is that it does suppose that the appropriate information is passed on from the cloud scheme to the radiative scheme. This aspect can explain the apparent paradox of the significant improvement of the LW bias to the east of the peninsula with three schemes, while no concomitant SW bias improvement is being observed. The discrepancies in SW and LW bias improvements will be further discussed in Sect. 5.1. Radiative schemes themselves also require careful examination as they also rely on various assumptions and simplified geometry to retrieve SW and LW fluxes. The radiative schemes that we used were chosen for consistency with K15 in order to compare their conclusions (using AMPS) to ours (using Polar WRF). We do not intend here to investigate the radiative schemes implemented in WRF. For further assessment of cloud microphysics schemes' performances and behaviours at a much wider scale, we now compare the simulation outputs to each other and to the cloud microphysics properties as measured during the BAS aircraft campaigns that took place over the Antarctic Peninsula (presented in part 1).

\section{Results: simulated clouds as compared to observations}

\subsection{General trends for simulated clouds across the peninsula}

The topography of the Antarctic Peninsula (Fig. 1) makes it interesting to focus on zonal distribution of latitudinal averages for the LWC (in $\mathrm{g} \mathrm{kg}^{-1}$ ) and the solid-water content (SWC, $\mathrm{g} \mathrm{kg}^{-1}$ ). SWC comprises ice, snow, and graupel mass. It is different from the IWC, which consists only of the mass of the cloud ice crystals. LWC and SWC were respectively averaged between latitudes 65.5 and $68.5^{\circ} \mathrm{S}$ and altitudes below $4500 \mathrm{~m}$. This geographical area includes the region where both flight campaigns took place in summer 2010 and 2011 (Fig. 1b). For simplicity we designate each simulation by using the name of its cloud microphysics scheme.

Both periods of interest display the same relative trends, and we present an average over both periods to give an overview. Averages are computed considering either all values, including null instances $\left(\mathrm{LWC}_{0}\right.$ and $\mathrm{SWC}_{0}$ in Fig. $4 \mathrm{a}$ and $b$, respectively), or only strictly positive values (LWC and SWC in Fig. 4c and d, respectively). Thus, we always have $\mathrm{LWC}_{0} \leq \mathrm{LWC}$ and $\mathrm{SWC}_{0} \leq \mathrm{SWC}$. LWC (SWC) gives the liquid (ice) content that is simulated disregarding how often the clouds form. $\mathrm{LWC}_{0}\left(\mathrm{SWC}_{0}\right)$ describes a more realistic average behaviour since it also accounts for the ability of the scheme to lead to liquid (ice) cloud formation, more or less often.

For all the simulations, $\mathrm{LWC}$ and $\mathrm{LWC}_{0}$ are in the interval $0.05-0.14$ and $0.002-0.03 \mathrm{~g} \mathrm{~kg}^{-1}$, respectively. SWC and $\mathrm{SWC}_{0}$ are in the interval $0.02-0.08$ and $0.01-0.035 \mathrm{~g} \mathrm{~kg}^{-1}$, respectively. The lower limit of $\mathrm{LWC}_{0}\left(0.002 \mathrm{~g} \mathrm{~kg}^{-1}\right)$ is due to WSM5's cloud liquid mass decreasing over the mountains down to $0.002 \mathrm{~g} \mathrm{~kg}^{-1}$ around $65^{\circ} \mathrm{W}$. For the other cloud schemes, $\mathrm{LWC}_{0} \geq 0.01 \mathrm{~g} \mathrm{~kg}^{-1}$. There is roughly a factor of 5 to 10 between $\mathrm{LWC}_{0}$ and LWC, while there is a factor of 1.2 to 2 between $\mathrm{SWC}_{0}$ and $\mathrm{SWC}$. The liquid phase features more important changes (from null to non-null values) than the total ice phase, which is simulated more frequently.

WSM5 strikingly differs from the Morrison, Thompson, and Milbrandt schemes in that its $\mathrm{LWC}$ and $\mathrm{LWC}_{0}$ decrease above the peninsula's mountains. LWC drops from $\sim 0.12 \mathrm{~g} \mathrm{~kg}^{-1}$ by more than $50 \%$ from 70 to $65^{\circ} \mathrm{W}$, before increasing back from 65 to $60^{\circ} \mathrm{W}$ to $\sim 0.12 \mathrm{~g} \mathrm{~kg}^{-1}$ (Fig. $4 \mathrm{c}$ ). Except east of $62^{\circ} \mathrm{W}$, where WDM6's LWC is larger than WSM 5 by less than $0.03 \mathrm{~g} \mathrm{~kg}^{-1}$ (not shown), both schemes display very similar averages for LWC and SWC, and we only show WSM5. LWC is much steadier for the three other 

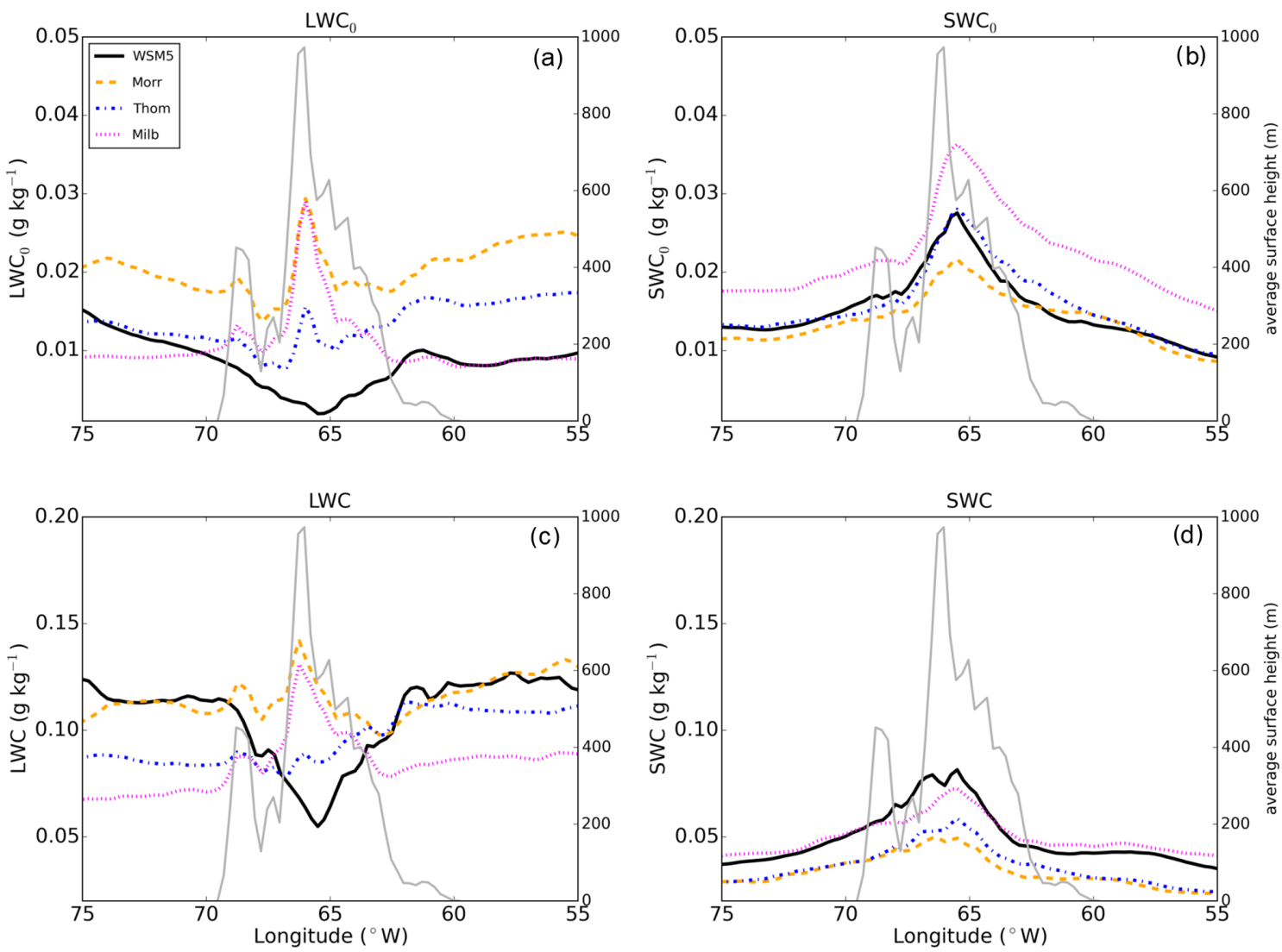

Figure 4. Longitudinal distribution of latitudinally $\left(65.5-68.5^{\circ} \mathrm{S}\right)$ averaged LWC and SWC $\left(\mathrm{g} \mathrm{kg}^{-1}\right)$ over both periods of interest for the WSM5, Morrison, Thompson, and Milbrandt schemes. The average is computed over all grid boxes and times, leading to (a) LWC $\mathrm{L}_{0}$ and (b) $\mathrm{SWC}_{0}$, or only over grid boxes and times where values are non-null, leading to LWC (c) and SWC (d). The thick grey line shows the surface height averaged over the same region and labelled on the right vertical axis of each plot. Note the identical scales used for the vertical axes for $\mathrm{LWC}_{0}$ and $\mathrm{SWC}_{0}$ and for $\mathrm{LWC}$ and $\mathrm{SWC}$.

schemes, and a sharp increase for the Milbrandt and Morrison schemes is observed above the highest terrains, caused by the orographic forcing induced by the westerlies or the easterlies (see Sect. 4.2).

The first obvious assessment with respect to the ability of the cloud schemes in forming (supercooled) liquid clouds is that WSM5 (WDM6) leads to less supercooled liquid mass than the Morrison, Thompson, and Milbrandt schemes across the Antarctic Peninsula. Eastward of $62^{\circ} \mathrm{W}$, WSM5's $\mathrm{LWC}_{0}$ is $100 \%(50 \%)$ smaller than Morrison's (Thompson's), while it is similar to Milbrandt's (Fig. 4a). However, in the central region over the mountains, WSM5 (and WDM6) leads to less liquid mass by up to an order of magnitude than the three other schemes. Westward of $69^{\circ} \mathrm{W} \mathrm{LWC}_{0}$ is similar for WSM5, Milbrandt, and Thompson; they are all twice as small as Morrison's LWC 0 . WSM5 does not lead as often as the other schemes to supercooled liquid formation, which is illustrated by its lowest $\mathrm{LWC}_{0}$ values, yet it does simulate as large average liquid water contents as the other schemes when and where liquid forms (similar LWC), except in the central region, where orographically induced clouds have systematically less liquid water. The ice phase instead shows a similar behaviour across the different cloud schemes with an increasing SWC closer to the high-altitude topography, due to orographic forcing. $\mathrm{SWC}_{0}$ is similar for WSM5, Morrison, and Thompson, while with Milbrandt it reaches $50 \%$ larger value largely due to the graupel mass (not shown).

Comparing $\mathrm{LWC}_{0}$ and $\mathrm{SWC}_{0}$, we see that the simulation with the Morrison scheme is the only one sustaining supercooled liquid mass more frequently than ice mass $\left(\mathrm{LWC}_{0}>\mathrm{SWC}_{0}\right.$ by a factor of $>1$ to 2$)$. For the Thompson scheme, $\mathrm{LWC}_{0} \sim \mathrm{SWC}_{0}$ on average (but $\mathrm{LWC}_{0}<\mathrm{SWC}_{0}$ over the mountains, and $\mathrm{LWC}_{0}>\mathrm{SWC}_{0}$ east of the Larsen $\mathrm{C}$ Ice Shelf). The Milbrandt scheme leads more often to ice mass formation than liquid mass $\left(\mathrm{LWC}_{0}<\mathrm{SWC}_{0}\right)$ by a factor of less than 2 at all longitudes, and WSM5 by a factor of 1 to 5. Finally, the simulation with WSM5 (WDM6) is the only one resulting in an anticorrelation between LWC $\left(\mathrm{LWC}_{0}\right)$ and $\mathrm{SWC}\left(\mathrm{SWC}_{0}\right)$ with an increase (decrease) for the cloud ice (cloud liquid) over the mountains. 

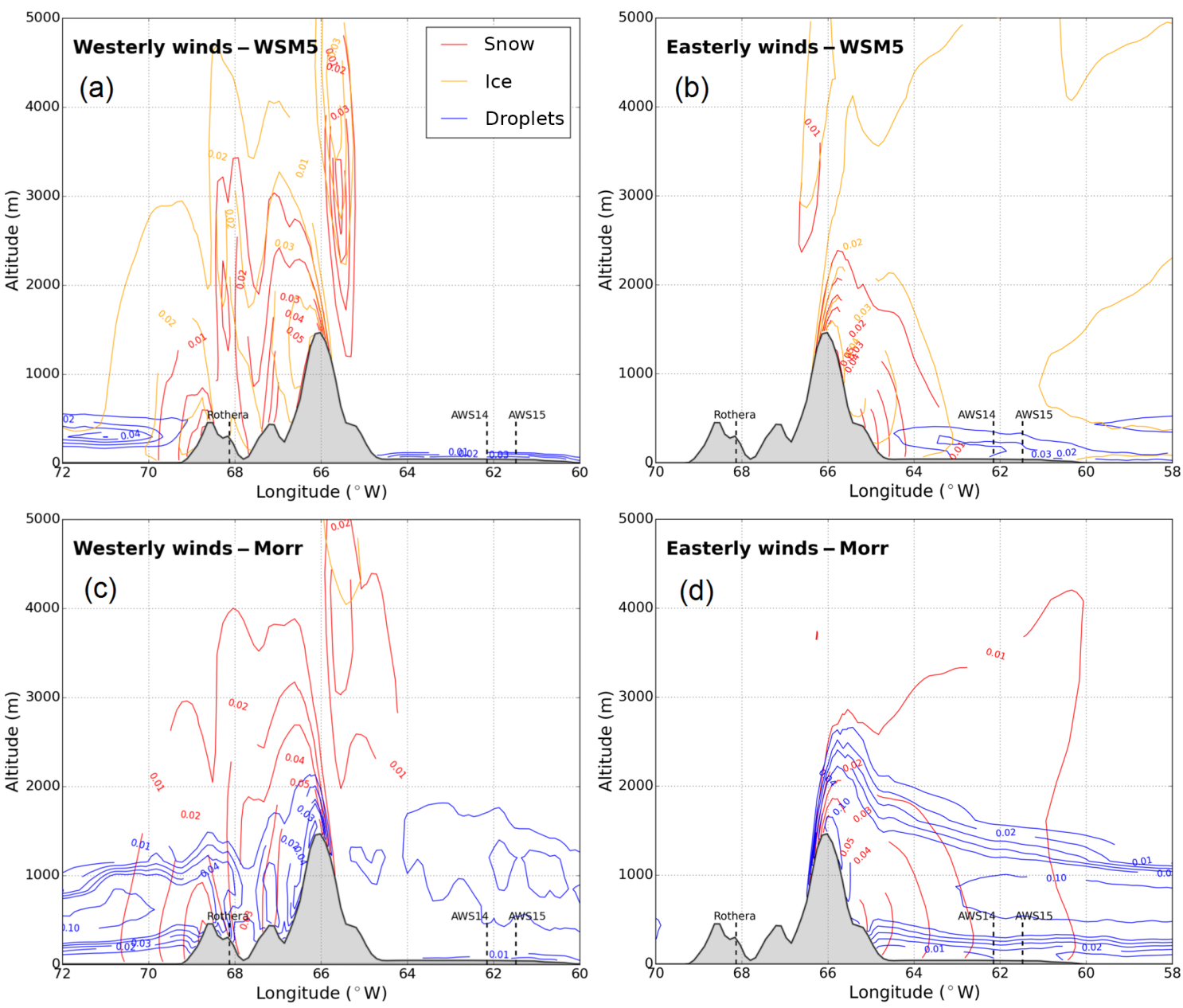

Figure 5. Transect of the cloud microphysics for WSM5 (a, b) and Morrison (c, d) averaged over a period (7-10 January 2011) dominated by westerly winds (a, c) and over another period (11-17 January 2011) dominated by easterly winds (b, d). The transect is approximately centred on Rothera Research Station $\left(67.586^{\circ} \mathrm{S}\right)$, and it is an average over a $100 \mathrm{~km}$ wide latitudinal band. The longitudes of Rothera, AWS14, and AWS15 are indicated.

\subsection{Dynamics and microphysics structure of the simulated clouds}

The Antarctic Peninsula's mountains act as a barrier to the westerly or easterly winds that drive the formation of orographic clouds. As a complement to the general picture given above, we identified one period of sustained westerly wind regime and one period of sustained easterly wind regime. We isolated the period 7 to 10 Januray 2011, when westerlies prevailed almost exclusively, and similarly the period 11 to 17 Januray 2011, when the easterly regime prevailed. Note that the average wind directions and speed, and their relative variations, are in agreement with upper-air measurements performed daily from Rothera Research Station (not shown), if not always quantitatively at least qualitatively, as well as with measurements from the aircraft (not shown).

Figure 5 shows time- and space-averaged transects of the hydrometeors' mass (including null instances) across the peninsula on a $\sim 100 \mathrm{~km}$ wide $\left(67-68^{\circ} \mathrm{S}\right)$ latitudinal band approximately centred on Rothera Research Station, for WSM5 (Fig. 5a and b) and the Morrison scheme (Fig. 5c and d). The westerly cases (panles b and d) and easterly cases (panels a and c) show the orographic clouds microphysical structure. They also illustrate the very different contexts of Rothera Research Station on the western side and of AWS14 and AWS 15 on the eastern side. Rothera itself is in the lee of a mountainous feature (Adelaide Island), and the topography adds to the complexity in simulating the clouds compared to the flat Larsen C Ice Shelf.

WSM5 predicts completely glaciated clouds on the peninsula and liquid clouds only away from the mountains with a very limited vertical extent (up to $500 \mathrm{~m}$ above the surface). The Morrison scheme maintains mixed-phase clouds across the region and at much higher altitudes. This fact alone is in better agreement with observations from the aircraft, which measured almost exclusively mixed-phase 
clouds (part 1). Over the ice shelf the snow increases from 0.01 to $0.05 \mathrm{~g} \mathrm{~kg}^{-1}$ as we get closer to the mountain barrier for all the schemes (similar amounts are simulated on the western side during the westerly regime). However, WSM5 simulates an IWC (orange lines) as large as the snow particles mass (red lines) down to the surface, contrasting very much with the Morrison scheme.

Note that WDM6 (not shown) gives similar results to WSM5. Also, the microphysical structure of the clouds predicted by the Thompson scheme and the Milbrandt scheme (not shown) are similar to the Morrison scheme. On either side of the peninsula, downwind, the Morrison scheme forms the most abundant mixed-phase cloud layer with LWC $\sim 0.1 \mathrm{~g} \mathrm{~kg}^{-1}$, and the clouds extends almost down to the surface ( $\mathrm{LWC} \sim 0.01 \mathrm{~g} \mathrm{~kg}^{-1}$ ), whereas the Milbrandt and Thompson schemes form less than half of that maximum amount, in line with the general picture given in Sect. 4.1. Also, the Milbrandt scheme forms a significant amount of cloud ice crystals (IWC) above $3000 \mathrm{~m}$, as well as graupel in the mixed-phase orographic clouds above the windward slopes (not shown), which are absent from the average transects of the Morrison and Thompson simulations.

\subsection{Microphysics schemes performances west and east of the Antarctic Peninsula}

\subsubsection{Liquid phase}

To assess the performances of the different cloud schemes, we compare the LWC measured from the aircraft to the simulated LWC by restraining the latter to the model grid boxes corresponding to the flight tracks. We only consider non-null $\mathrm{LWC}$ values ( $\mathrm{LWC}>0.001 \mathrm{~g} \mathrm{~kg}^{-1}$ ). For each data point, the closest (both in time and space) grid box value is extracted from the model. Latitudinal averages are derived for each flight per $0.5^{\circ}$ longitude bins, for simulations and observations. At the latitude of Rothera Research Station $\left(67.586^{\circ} \mathrm{S}\right)$ this corresponds to $\sim 10 \mathrm{~km}$ (i.e. two grid boxes). Then, global west and east averages are derived, corresponding to longitudes westward of $67^{\circ} \mathrm{W}$ and to longitudes eastward of $65^{\circ} \mathrm{W}$, respectively (as in part 1 ). LWC is derived as presented in part 1 using the droplet size distribution obtained from the CAS.

The unknown thermodynamic phase of the smallest particles seen - but not resolved - by the CIP, and that can be either drops or small crystals (see part 1), may induce a bias in the derivation of LWC. However, if all of them were counted as droplets, they would increase LWC by $\leq 8 \%$ for all flights except two flights in 2010 (13 and 30\%) and one flight in $2011(12 \%)$. This bias does not alter the results or the conclusions below. More information on the instruments and the measurement can be found in part 1 (their Sect. 2.1).

Figure 6 shows the scatter plots of simulated LWC versus observed LWC for 2010 (Fig. 6a and b) and 2011 (Fig. 6c and d) and for either side of the peninsula, west (panels a and c)
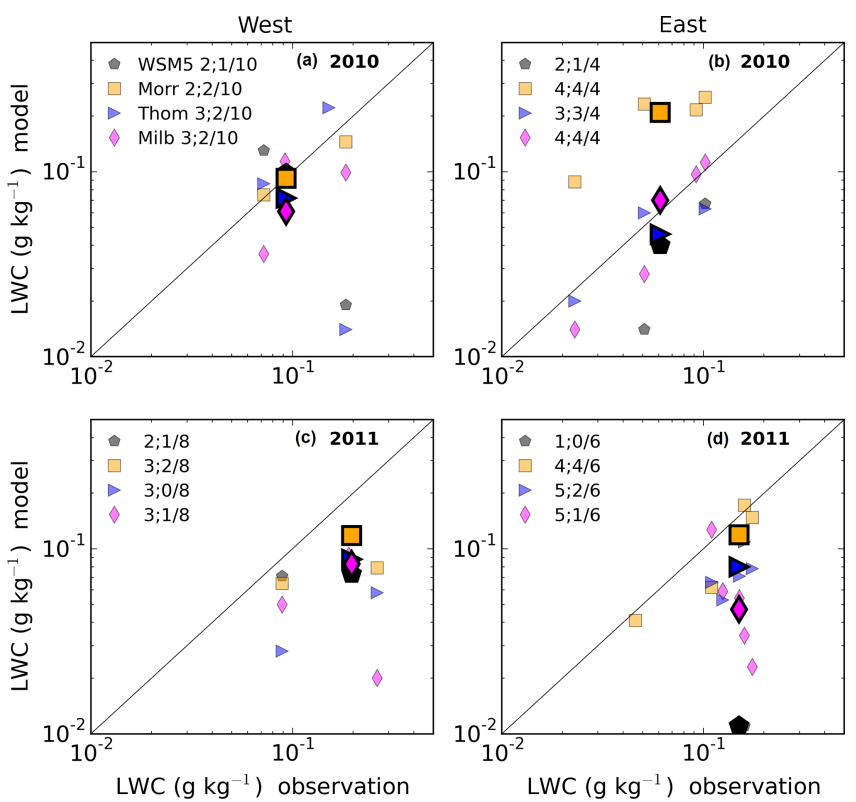

Figure 6. Scatter plot of simulated LWC versus observed LWC in 2010 (a, b) and in 2011 (c, d) on the western side of the peninsula $(\mathbf{a}, \mathbf{c})$ and on the eastern side of the peninsula (b, d). Light markers show averages per flight track, while bold markers give the average of all the tracks on each side of the peninsula. The numbers next to each scheme's marker in the legend $\left(n_{5} ; n_{50} / N\right)$ gives the number $n_{5}\left(n_{50}\right)$ of simulated flights with a simulated LWC at least $5 \%(50 \%)$ of the observed LWC to the total number $N$ of flights measuring an average LWC. Note that in panel (c) the bold markers (total average) overlay some light markers (flight averages), which explains the actual higher position of the total average on the graph compared to the other discernible lower flight averages.

and east (panels $b$ and d). Regional (east or west) averages are represented by the largest bold markers, while smaller markers relate to individual flight averages. Note that the width of the large markers is larger than the length of the error bar associated with the aforementioned error (bias) related to the LWC derivation. The numbers shown next to each scheme's markers in the legend (in the form $n_{5} ; n_{50} / N$ ) indicate the number of flight tracks for which the simulation forms at least an average of $5 \%\left(n_{5}\right)$ or $50 \%\left(n_{50}\right)$ of the observed average LWC, over the total number of flight tracks $(N)$ having measured cloud liquid. We refer to those as the $n_{5}$ criterion and the $n_{50}$ criterion, respectively.

Three results stand out. First, all the schemes perform worse in the west than in the east in terms of number of tracks with simulated clouds ( $n_{5}$ and $n_{50}$ criteria) except for the WSM5 scheme, which performs equally bad on both sides. Second, the WSM5 scheme has the lowest numbers of flights with some liquid clouds simulated ( $n_{5}$ criterion). For the Morrison, Thompson, and Milbrandt schemes, about (Fig. 6a) or much less than (Fig. 6c) $30 \%$ of flights are predicted with some substantial supercooled liquid $\left(n_{50}\right.$ criterion) in the west and more than $60 \%$ of them in the east 
(Fig. $6 \mathrm{~b}$ and d). Third, the Morrison scheme performs on average the best in reproducing observed LWC in the western and the eastern portions of the flight tracks, with larger values of LWC simulated than for the other schemes. When considering the $n_{5}$ criterion, the Thompson and Milbrandt schemes show equally good scores compared to Morrison, suggesting the same ability to initiate a non-negligible supercooled liquid phase, as opposed to WSM5 (and especially on the eastern side). However, overall the Morrison scheme performs better because it has an averaged simulated LWC closer to the observed one within a factor of less than 2 (except in the east in 2010 - Fig. $6 b$ - where it simulates an average LWC 3 times larger than the observations).

Those averages do not take into account the duration over which such values are observed. Thus, we use an additional metric that is the average time spent in cloud (or instances of cloud occurrences) on either side of the peninsula. The average ratio of the time spent in clouds in the model (with LWC $>0.01 \mathrm{~g} \mathrm{~kg}^{-1}$ ) over the one in the measurements is given in Table 5 for each side and year. The average is derived as an average of the flight averages. Over both periods the best scheme appears to be the Morrison scheme since the Thompson and Milbrandt schemes have very low occurrences of clouds compared to the observation on the western side, with $4 \%$ in 2011 and 5\% in 2010, respectively. On the eastern side, WSM5 has the poorest performance $(<1 \%)$, and the Morrison scheme has twice as many occurrences of clouds (although still quite low) in 2011 as the two other schemes, and it overpredicts the formation of clouds in 2011 (215\%), although not the average LWC (Fig. 6d).

Average vertical profiles of cloud liquid (and ice) were also derived for flights measurements as well as for the model outputs. The altitude grid on which flights observations, and model outputs, were averaged is finer in its lower layers, with one level every $100 \mathrm{~m}$ below $1100 \mathrm{~m}$ and every $200 \mathrm{~m}$ above $1100 \mathrm{~m}$. At each altitude level the average of the flight averages is computed so that every flight has the same weight. Model altitude levels are separated by less than $1000 \mathrm{~m}$ at the highest altitude levels of the atmospheric column. However, below $4500 \mathrm{~m}$, where the flights took place, the maximum model level separation is approximately $500 \mathrm{~m}$. Thus, any data point level is less than $250 \mathrm{~m}$ away from the closest model level (less than $100 \mathrm{~m}$ below $1100 \mathrm{~m}$ ). Figure 7 compares vertical distribution of observed (grey circles) and simulated (coloured markers) non-null average LWC $\left(>0.001 \mathrm{~g} \mathrm{~kg}^{-1}\right)$ for WSM5 (top) and the Morrison scheme (bottom). The grey shaded area shows the spread of all flight averages. The error bars show the spread of the simulated flight averages. The numbers at each level indicate how many simulated flights with non-null averages are used to derive the total average of each level, for the simulations as compared to (" $/$ ") the observations.

The WSM5 scheme does not form liquid clouds above $800 \mathrm{~m}$ on the western side of the peninsula or above $500 \mathrm{~m}$ on the eastern side during both periods of interest. Liquid clouds
Table 5. Average ratio (\%) of the number of occurrences of LWC $>0.01 \mathrm{~g} \mathrm{~kg}^{-1}$ in the simulations over the observations. The average is derived from the flight averages.

\begin{tabular}{lrrrr}
\hline $\begin{array}{l}\text { Region } \\
\text { year }\end{array}$ & WSM5 & Morrison & Thompson & Milbrandt \\
\hline West 2010 & 47 & 72 & 69 & 5 \\
West 2011 & 54 & 49 & 4 & 88 \\
East 2010 & $<1$ & 7 & 3 & 3 \\
East 2011 & $<1$ & 215 & 130 & 105 \\
\hline
\end{tabular}

were observed as high as $4400 \mathrm{~m}$. The numbers at each level show that WSM5 simulates fewer occurrences of liquid than the Morrison scheme, which still underpredicts the occurrences of liquid clouds. The Morrison scheme shows liquid cloud formation up to $2500 \mathrm{~m}$, albeit only very few instances above $1500 \mathrm{~m}$.

WDM6 shows no improvement compared to WSM5 (not shown). The Milbrandt and Thompson schemes simulate liquid clouds more often than WSM5 in the lowest layers, but no clear systematic difference emerges between those two and the Morrison scheme. The Morrison scheme simulates best the increasing trend of LWC with altitude in the west in 2011. It has the largest LWC below $1000 \mathrm{~m}$ (by $0.1-0.2 \mathrm{~g} \mathrm{~kg}^{-1}$ ) on either side of the peninsula in 2010 compared to other schemes, while LWC is comparable for all the three schemes in 2011 (not shown).

\subsubsection{Ice phase and mixed phase}

For completeness we compare the simulated SWC $\left(\mathrm{g} \mathrm{kg}^{-1}\right)$ to the observed ice mass. Figure 9 is the same as Fig. 6 but for SWC, with the addition of the corresponding IWC regional averages shown as large light grey markers. (The latter are slightly shifted rightwards by $50 \%$ of the observed value on the $x$ axis in order to be visible.) The smaller and lightcoloured markers are individual flight averages. The same $n_{5}$ criterion and $n_{50}$ criterion as in Fig. 6 are used and referenced in Fig. 9 next to each cloud scheme's name.

As mentioned in part 1, there is an uncertainty in the smallest particles detected by the CIP; however they contribute to a negligible amount of the total measured ice mass. At the other end of the size distribution, the maximum cutoff for detected ice particles is about $1.5 \mathrm{~mm}$ in size (diameter). Thus possible larger particles that could significantly add to the mass are not detected. However, in order to have an estimate of the error caused by the missed larger particles, we approximated and extrapolated the average size distribution of the crystals for each flight (examples are shown in Fig. 8a and b), using an exponential distribution of the form $N(D)=N_{0} \exp (-\lambda D)$ (known as Marshall-Palmer distributions) commonly used for the rain and the ice hydrometeors in the cloud microphysics schemes (e.g. Morrison et al., 2009). Using the exponential distribu- 

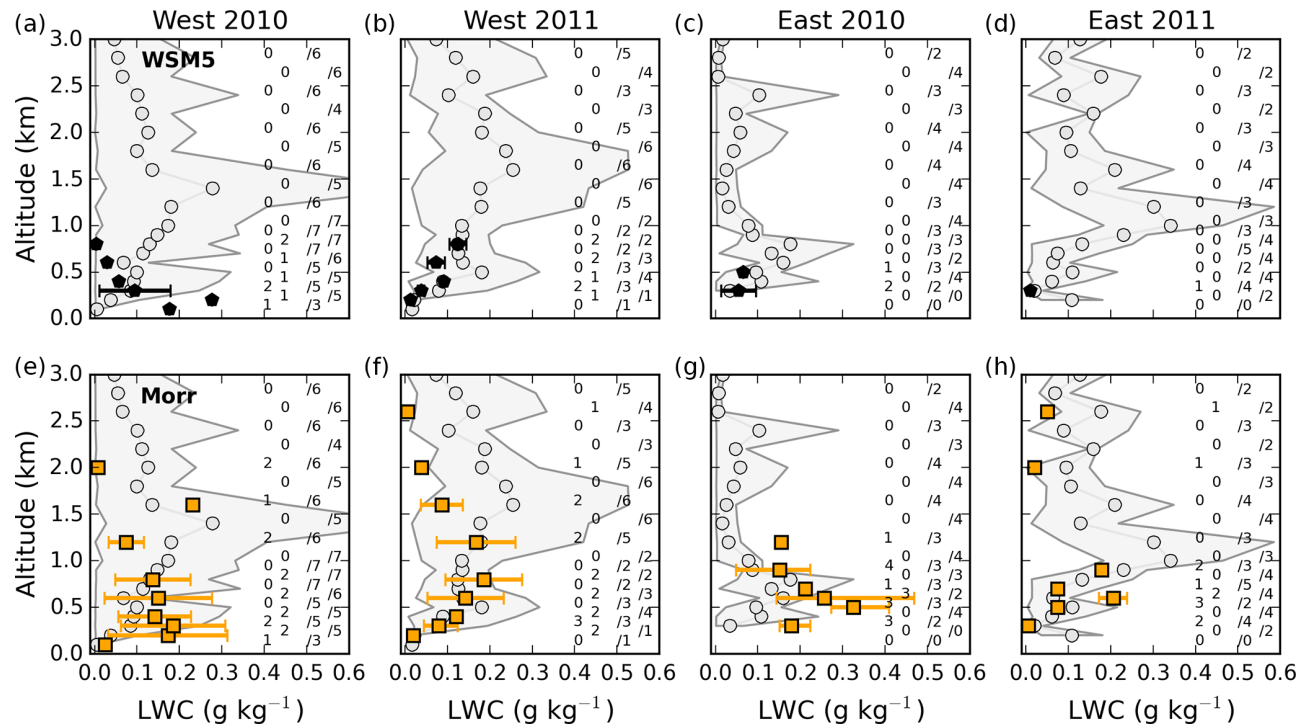

Figure 7. Averaged vertical profiles of non-null LWC for WSM5 (a-d) and the Morrison scheme (e-h) and for the observations west $(\mathbf{a}, \mathbf{b}, \mathbf{e}, \mathbf{f})$ and east $(\mathbf{c}, \mathbf{d}, \mathbf{g}, \mathbf{h})$ of the peninsula. Grey markers indicate the measured average at each altitude, while the shaded area gives the range of the observed flight averages at each altitude. Similarly, coloured markers and error bars relate to the cloud schemes. The numbers indicate how many simulated flight averages were used to derive the global average at each altitude for each scheme, as compared to ("/") for the observations.
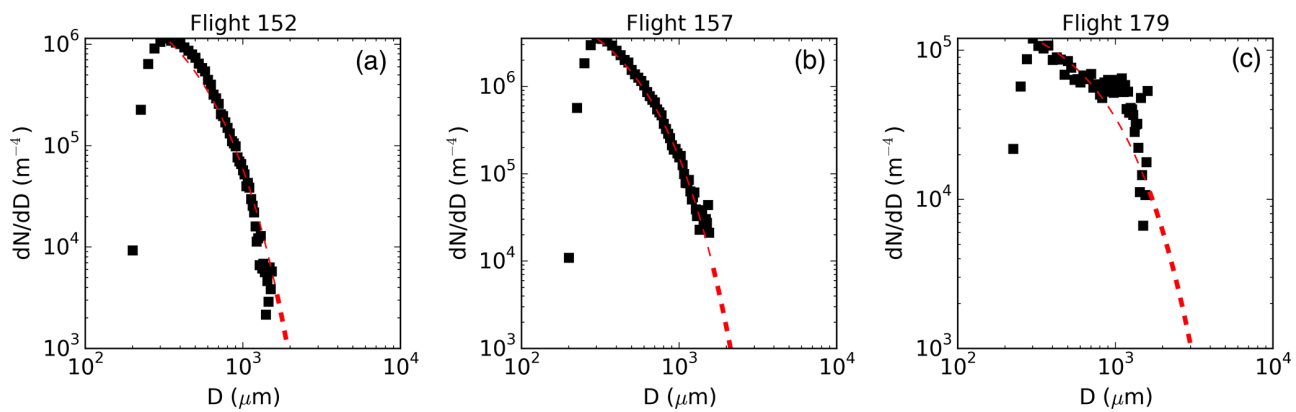

Figure 8. Average size distribution of the crystals identified with the CIP for the flights (a) 152, (b) 157, and (c) 179 (black squares), along with the exponential distribution approximating them (red dashed line). The relative increase in ice mass when further integrating from $1.5 \mathrm{~mm}$ to larger diameters (equal to the relative error on the actual ice mass used in this study) is about $3 \%$ (a), $2.5 \%$ (b), and $65 \%$ (c) (see text for details).

tion and the mass-diameter law, we derive an ice water content below $1.5 \mathrm{~mm}$ and above $1.5 \mathrm{~mm}$, respectively. In order to derive the mass for $D \leq 1.5 \mathrm{~mm}$, we integrated over the crystal sizes starting from the peak diameter of the distribution and up to $1.5 \mathrm{~mm}$. The peak diameter of the observed ice crystal distribution is located in the range $250-425 \mu \mathrm{m}$ (with an average of $315 \mu \mathrm{m}$ ), a value from which the exponential distribution can approximate the distribution of the largest crystals. Then, the ice water content for particles with $D>1.5 \mathrm{~mm}$, and up to an arbitrary limit of $3.2 \mathrm{~mm}$, was derived (setting the upper limit to even larger sizes does not change the resulting additional ice mass given the even lower amounts of crystal number concentration predicted by the exponential distribution). The ratio of both ice water contents allows estimating the relative error caused by the undetected particles on the measured SWC when assuming an exponential distribution. For the 2010 flights, this average error is about $5 \%$, including an outlier flight with a $33 \%$ error (ignoring this flight brings the average error to $2 \%$ ). For the 2011 flights, the average relative error is about $8 \%$, including an outlier with a $65 \%$ error (shown in Fig. 8c) (ignoring this flight brings the average error to $2 \%$ ). The large error derived for the two flights is related to a shoulder of the crystal distribution for the larger particles, leading to an exponential distribution predicting a number concentration of the largest particles likely to be in large excess compared to the actual one (Fig. 8c). Overall, these estimates of the relative errors in SWC do not alter the main conclusions presented here.

Table 3 gives the cut-off radii between ice particles and snow particles in the different cloud schemes. The different 

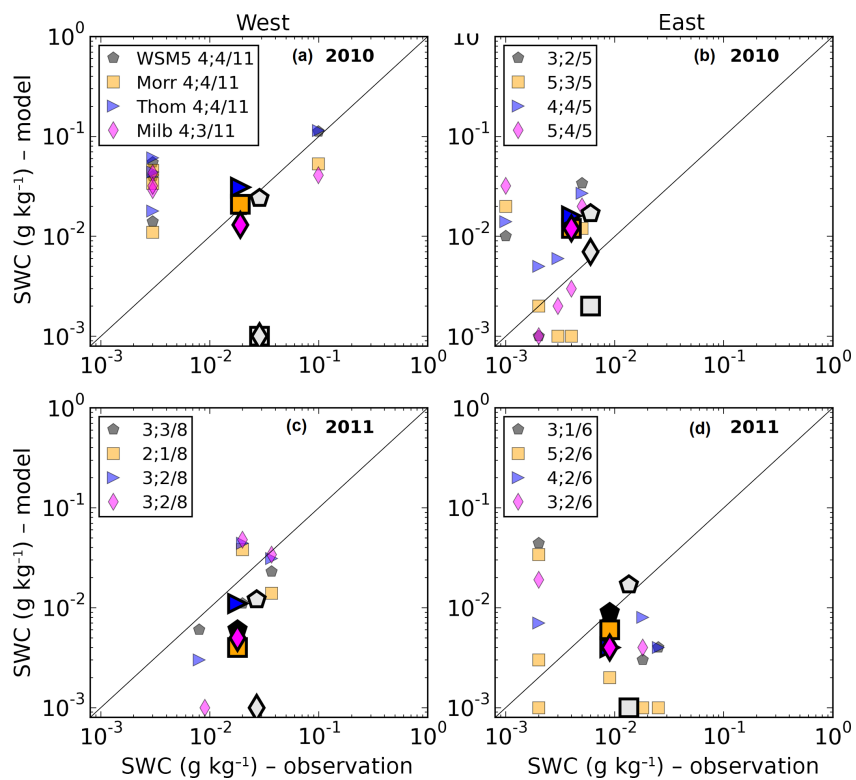

Figure 9. Scatter plot of simulated solid-water content (SWC; ice, snow, graupel) versus observed SWC in 2010 (a, b) and in 2011 (c, d) on the western side of the peninsula (a, c) and on the eastern side of the peninsula (b, d). The small light-coloured markers show the average per flight, while large coloured bold markers give the average over the whole tracks on each side of the peninsula. The large light grey markers show the simulated ice water content (IWC) averages corresponding to each simulated SWC average (for readability each light-grey marker is slightly shifted on the $x$ axis by $50 \%$ of the measured value). The numbers next to each scheme's name $\left(n_{5} ; n_{5} 0 / N\right)$ give the number $n_{5}\left(n_{50}\right)$ of simulated flights with a SWC of at least $5 \%(50 \%)$ of the observed SWC to the total number $N$ of flights measuring an average ice content of at least $0.0001 \mathrm{~g} \mathrm{~kg}^{-1}$.

definitions of the icy hydrometeors across the cloud schemes add to the difficulty of performing comparisons between the schemes as well as the observations. The observed particles identified unambiguously as crystals in part 1 span the diameter range $200 \mu \mathrm{m}$ to $1.5 \mathrm{~mm}$. Hence, because the cloud microphysics schemes have a lower limit size smaller than $200 \mu \mathrm{m}$ for the ice crystal and an upper limit size larger than $1.5 \mathrm{~mm}$ for the precipitating ice particles (snow, graupel ;see Table 3), we expect the simulated IWC and SWC to bracket the observations. However, the measured ice mass should be closer to SWC than to IWC given the relatively low additional mass expected from particles with $D>1.5 \mathrm{~mm}$ using the estimates presented above.

In 2010, the instances where SWC and IWC do bracket the observations happen on both sides of the peninsula (Fig. 9a and $b$ ) for the Morrison and Thompson schemes (note that the Thompson scheme's IWC is between $10^{-4}$ and $10^{-3} \mathrm{~g} \mathrm{~kg}^{-1}$ ). WSM5's SWC and IWC equal the observation, showing that a significant part of the simulated SWC is on average in the form of cloud ice crystals (IWC) (i.e. radii $<250 \mu \mathrm{m}$; see Ta- ble 3). In 2010, west of the peninsula, Milbrandt's SWC and IWC are lower than the observations, suggesting not enough ice formation.

In 2011 (Fig. 9c and d), all the scheme have both averaged SWC and IWC lower than the observations, except for WSM5 to the east of the peninsula, where the averaged IWC exceeds the observed value. East of the peninsula, all the schemes predict equally well some non-negligible ice phase ( $n_{5}$ criterion), with Morrison, Thompson, and Milbrandt performing better than WSM5 when considering the $n_{50}$ criterion. However, the schemes perform worse west of the peninsula, with less than $40 \%$ of ice occurrences actually simulated ( $n_{5}$ criterion). Overall, As for the liquid phase, the occurrences of the ice phase are less well simulated on the western side of the peninsula than on its eastern side.

Finally, we focus on the partition of water between the condensed phases, LWC, and SWC by looking at the total average mixed-phase ratio $f_{\mathrm{m}}=\mathrm{LWC} /(\mathrm{LWC}+\mathrm{SWC})$ as a function of temperature along the flight tracks. Table 6 summarizes the statistics on $f_{\mathrm{m}}$ derived from measurements and from simulations. First, none of the schemes sustain liquid clouds at temperatures below $-15^{\circ} \mathrm{C}$, or even below $-9{ }^{\circ} \mathrm{C}$ for the WSM5 (WDM6) scheme (leading to $f_{\mathrm{m}}=0$ ). This will be further commented on in Sect. 5.2. Second, between -15 and $0{ }^{\circ} \mathrm{C}$, the Morrison scheme $(0.91 \pm 0.1)$ and the Milbrandt scheme $(0.78 \pm 0.1)$ have an average $f_{\mathrm{m}}$ in closest agreement with observations $(0.83 \pm 0.08)$. WSM5 performs the least well, with $f_{\mathrm{m}}$ around 0.6 on average and down to 0.07 at its minimum. WSM5 $(\sigma=0.24)$ and the Thompson scheme $(\sigma=0.2)$ have a variability of $f_{\mathrm{m}}$ more than twice as large as the observations $(\sigma=0.08)$. Practically, for WSM5 and the Thompson scheme, it results in a highly variable mixed-phase ratio from one $0.5^{\circ}$ temperature bin to the next, which is not observed in the measurements (not shown). The Morrison scheme $(\sigma=0.1)$ and the Milbrandt scheme ( $\sigma=0.1$ ) have a steadier $f_{\mathrm{m}}$ across the investigated temperature range where mixed-phase clouds are simulated, in closer agreement to the observations.

\subsection{Temperatures and water vapour in Polar WRF over the flight campaigns}

We take advantage of temperature and water vapour measurements performed along with the cloud in situ measurements to compare with the averaged simulation outputs. Latitudinal averages (in $0.5^{\circ}$ longitude bins) for both observations and simulations are shown for temperatures $\left({ }^{\circ} \mathrm{C}\right)$ and water vapour mass mixing ratios $\left(\mathrm{g} \mathrm{kg}^{-1}\right)$ in Fig. 10a and b, respectively. The variability of the water vapour and of the temperature (shown as the standard deviation of the flight averages in each longitude bin) is indicated with shaded area for the observations and with error bars for the different cloud schemes. The measurement uncertainty for the temperature measured with a Rosemount probe is about $0.3^{\circ} \mathrm{C}$ (Stickney et al., 1994), corresponding to less than the width of the solid 
Table 6. Statistics over the flight tracks on the mixed-phase ratio $f_{\mathrm{m}}=\mathrm{LWC} /\left(\mathrm{LWC}+\mathrm{SWC}\right.$ ) for temperatures $T>-15^{\circ}$ (see text for details).

\begin{tabular}{lrrrrr}
\hline$f_{\mathrm{m}}$ & Observation & WSM5 & Morrison & Thompson & Milbrandt \\
\hline Average & 0.84 & 0.6 & 0.91 & 0.66 & 0.79 \\
$\sigma$ & 0.08 & 0.24 & 0.1 & 0.20 & 0.10 \\
Max & 0.94 & 0.9 & 1 & 0.92 & 0.95 \\
Min & 0.60 & 0.07 & 0.61 & 0.21 & 0.56 \\
\hline
\end{tabular}

blue and red lines. The darkest narrow shaded areas bracketing solid lines on both years correspond to a conservative estimate of uncertainty on water vapour $\left( \pm 0.15 \mathrm{~g} \mathrm{~kg}^{-1}\right)$ as derived using the relative humidity measured with a Vaisala HUMICAP HMP45 ( $\pm 3 \%$ estimated relative error) and the atmospheric temperature measurements from the Rosemount probe. A Buck 1011C cooled-mirror hygrometer also present on board was used to correct for an offset in the HUMICAP measurements. At low temperatures and humidity the cooled-mirror hygrometer occasionally has difficulty in identifying the frost point correctly and tends to hunt over a wide range. Therefore the HUMICAP measurements were used once corrected using the cooled-mirror hygrometer during periods when we are confident that it has correctly identified the frost point.

For the temperature, in 2010 all the simulations show best agreement with the measurements to the east of the peninsula, where the overestimation of the temperature ranges between 0 and $1{ }^{\circ} \mathrm{C}$ (Fig. 10a, top). Westward of $65^{\circ} \mathrm{W}$ the positive biases are larger and range between 1 and $2{ }^{\circ} \mathrm{C}$. In 2011 and east of the peninsula, the temperature bias lies between 1 and $2{ }^{\circ} \mathrm{C}$, whereas west of $69^{\circ} \mathrm{W}$ it ranges between 2 and $3{ }^{\circ} \mathrm{C}$ with the exception of the Thompson scheme leading to overestimations as large as $4^{\circ} \mathrm{C}$ (Fig. 10a, bottom).

For the water vapour, the 2011 observed average is underestimated at almost all longitudes except between 68.5 and $64^{\circ} \mathrm{W}$, where it is overestimated by $0.15 \mathrm{~g} \mathrm{~kg}^{-1}$ on average (Fig. 10b, top). Eastward of $63^{\circ} \mathrm{W}$, the underestimation increases up to values closer to $1 \mathrm{~g} \mathrm{~kg}^{-1}$, while westward of $71^{\circ} \mathrm{W}$ it remains around $0.5 \mathrm{~g} \mathrm{~kg}^{-1}$. In 2010 the average water vapour is underestimated by $0.2-0.5 \mathrm{~g} \mathrm{~kg}^{-1}$, except west of $68^{\circ} \mathrm{W}$ where it reaches $1 \mathrm{~g} \mathrm{~kg}^{-1}$ (Fig. 10b, bottom). The bias then decreases to around $0.25 \mathrm{~g} \mathrm{~kg}^{-1}$ in the area $67.5-63.5^{\circ} \mathrm{W}$, except for WSM5, which remains closer to $0.5 \mathrm{~g} \mathrm{~kg}^{-1}$. Eastward of $62^{\circ} \mathrm{W}$ the underestimation increases up to $1 \mathrm{~g} \mathrm{~kg}^{-1}$, but only one flight measured water vapour, hence the poor statistics (as shown by the absence of shaded area). WSM5 has the largest biases in averaged water vapour during both years, 0.6 and $0.45 \mathrm{~g} \mathrm{~kg}^{-1}$ in 2010 and 2011, respectively, mostly consisting of an underestimation of the observed water vapour. Other schemes also mostly underestimate the water vapour, albeit less than WSM5 by $0.05-0.1 \mathrm{~g} \mathrm{~kg}^{-1}$. No cloud scheme clearly stands out in terms of reducing the negative bias. (a)
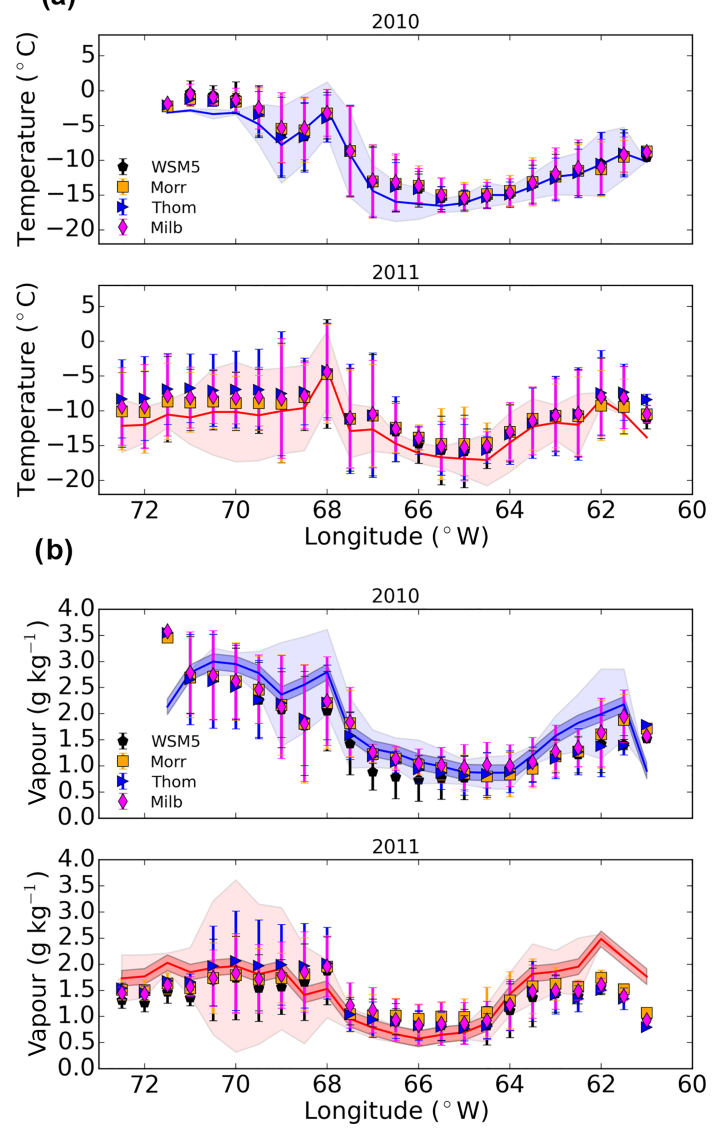

Figure 10. Zonal distribution for 2010 and 2011 flight campaigns of averaged (a) temperature and (b) water vapour $\left(\mathrm{g} \mathrm{kg}^{-1}\right)$. Measurements are shown as a solid line, and simulations as markers. Shaded areas and error bars give the standard deviation in each $0.5^{\circ}$ longitude bin for the observation and the simulations, respectively. The dark shaded area corresponds to a conservative estimate of the uncertainty on water vapour (see text for details).

Overall across the peninsula the simulations underestimate the measured water vapour by an average value of $0.5 \mathrm{~g} \mathrm{~kg}^{-1}\left( \pm 0.2 \mathrm{~g} \mathrm{~kg}^{-1}\right.$, depending on schemes or regions across the peninsula), and the temperatures are overestimated by $1{ }^{\circ} \mathrm{C}\left( \pm 0.2^{\circ} \mathrm{C}\right.$, depending on the scheme $)$ in 2010 and $2{ }^{\circ} \mathrm{C}\left( \pm 0.5^{\circ} \mathrm{C}\right.$, depending on the scheme $)$ in 2011 . Interestingly, the variabilities of the observations (shaded area) and of the simulations (error bars) are consistent with each other. This suggests a good performance of the model average and variability. The broad agreement in temperature and water vapour between the simulations suggests that their differences in average simulated clouds cannot be mainly related to the differences in water vapour and temperature, but rather to their microphysics. The biases compared to the observation will be further commented on in the Sect. 5.4. 


\section{Discussion}

\subsection{On the radiative biases}

A deficiency of downward LW radiation responsible for a cold summer surface (temperature) bias in Polar WRF simulations was spotted at a continental scale by Bromwich et al. (2013a) at 60 and $15 \mathrm{~km}$ resolution, and the authors related this bias to a deficiency in the cloud cover. Bromwich et al. (2013a) showed that using ERA-Interim analysis forcing at the domain boundaries (instead of GFS analysis) helped to significantly reduce the average cold summer bias (see their Table 5), although the improvement for surface pressure or dew point is not clear. The simulation outputs of Bromwich et al. (2013a) as well as K15's AMPS results relied on the WSM5 scheme. We did find a similar negative bias for the LW radiation to K15 over the Larsen C Ice Shelf, as well as a similar positive bias for the SW radiation (Sect. 3.1).

When schemes different from WSM5 or WDM6 are used with Polar WRF in our simulations, a strong decrease in the LW bias for both periods of interest over the Larsen C Ice Shelf is measured. This suggests that schemes like the Morrison, Thompson, or Milbrandt schemes should be preferred to the WSM5 and WDM6 schemes in studies dealing with the evolution of the energy budget of the Larsen C Ice Shelf within Polar WRF. The strong decrease in LW surface biases (by as much as $20 \mathrm{~W} \mathrm{~m}^{-2}$; see Table 4) when using the three cloud schemes, which have a more sophisticated ice microphysics parameterization (double moment), is systematically statistically significant in both years and at both AWSs (AWS14 and AWS15). Note that the smallest biases are obtained using the Morrison scheme.

The explanation as to why the LW bias is significantly improved while the SW is not always (especially in 2010) is most probably that the variations of the cloud droplet effective radius is not accounted for in the radiative scheme. The latter (Goddard scheme; see Table 1) parameterizes the optical depth for water and ice as a function of the particle effective radius (Chou and Suarez, 1999). This parameterization does not assume any type of droplet (crystal) size distribution, so it can be used with the different cloud schemes despite their own different assumptions on the hydrometeor size distributions. Also, the SW radiative scheme assumes a constant value of $10 \mu \mathrm{m}$ for the cloud droplet effective radius. However, for a given LWC, the SW radiation is scattered in different ways depending on the effective radius of the droplets, with smaller radii reflecting more efficiently SW radiation. The droplet effective radius derived for both aircraft campaigns is about $7 \mu \mathrm{m}$, close to the $10 \mu \mathrm{m}$ assumed in the radiative scheme. Running a simulation over a shorter period (11-20 January 2011) replacing the constant effective radius of $10 \mu \mathrm{m}$ by a constant $7 \mu \mathrm{m}$ in the radiative scheme did not lower the SW radiative bias over the Larsen C Ice Shelf (not shown). This was expected as it is rather the variations of the effective radius with time that could be expected to im- prove the SW bias. As noted by Bromwich et al. (2013a), the SW bias is of secondary importance for the surface energy budget because SW radiation not reflected by missing clouds in the model will be reflected by the icy or snowy surface underneath. The cloud radiative effect dominates in the LW radiation over icy surfaces (as opposed to over the ocean).

The poorer performances of the various simulations in terms of surface radiation biases at Rothera Research Station (Table 4, left part) and especially the similarly large LW surface biases for all the schemes are consistent with a poorer representation of the supercooled liquid clouds in the western part of the peninsula (Fig. 6). Indeed, only a few flight tracks were simulated with supercooled liquid phase ( 3 out of 11 and 3 out of 10 at best in 2010 and 2011, respectively). This is further commented on in Sect. 5.2, where we discuss the simulation of the cloud phase.

\subsection{Simulating the cloud thermodynamic phase}

Cloud schemes form supercooled liquid provided the growth of the activated ice phase does not consume the entire excess of water vapour (compared to $\mathrm{RH}=100 \%$ ). While the Milbrandt scheme completely removes the supersaturation by conversion of the excess of water vapour into liquid, the other schemes explicitly derive a condensation growth rate. Thus, the cloud microphysics schemes mainly differ in their ice microphysics and mixed-phase interactions, which will determine their ability to form and maintain supercooled liquid in the atmosphere.

WSM5 (WDM6) is the only microphysics scheme showing an anticorrelation of the liquid water content and solid water content on the peninsula, suggesting a systematic depletion of water vapour in favour of the ice phase (Fig. 4). Close to and above the topography WSM5 has a deficit in liquid clouds due to orographic forcing which favours ice clouds, whereas the Morrison, Milbrandt, and Thompson schemes have a steady if not increasing LWC. One of the main differences between WSM5 and WDM6 (hereafter called the WRF schemes) and the other three schemes is that the former are single-moment schemes for the icy hydrometeors, whereas the latter are double-moment schemes for the ice crystals (only the Thompson scheme is not a doublemoment scheme for snow/graupel particles). A consequence of the WRF schemes being single-moment schemes for the ice crystals is the use of a relationship for linking the number concentration of ice crystals $\left(N_{\mathrm{i}}\right)$ to the ice water content $\left(q_{\mathrm{i}}\right)$, since they cannot evolve independently. $N_{\mathrm{i}}$ is diagnosed from $q_{\mathrm{i}}$ based on empirical relationships (see Eqs. 5a-d in Hong et al., 2004, where $N_{\mathrm{i}}$ is proportional to $q_{\mathrm{i}}^{3 / 4}$ ). In addition to that, the INP parameterization used in the WRF schemes predicts significantly more INPs than any other parameterization above $-15^{\circ} \mathrm{C}$ (as will be shown in the next Sect. 5.3). Since it is used to predict the initial $q_{\mathrm{i}}$ when the first ice appears, the latter is biased towards larger-than-expected values, and so $N_{\mathrm{i}}$ will also be biased towards larger values (because of the 

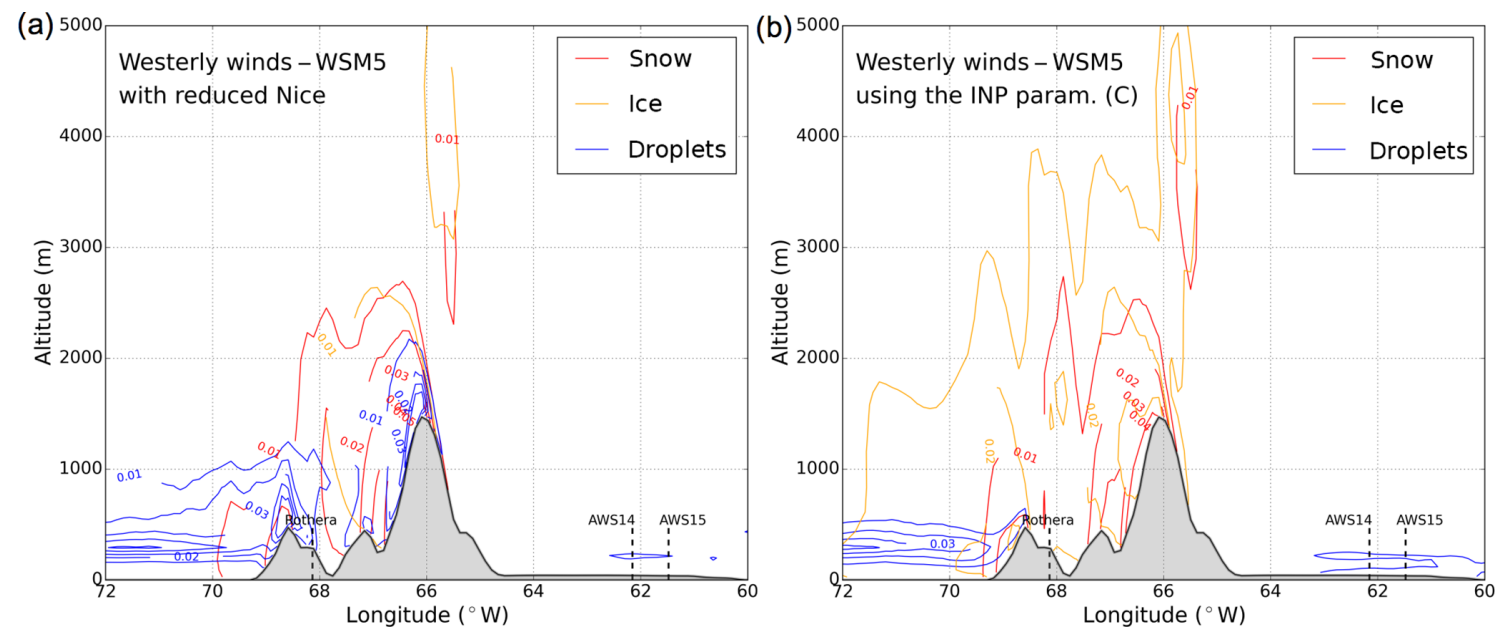

Figure 11. Same as Fig. 5a but with (a) a modified version of WSM5 where the empirical relationship linking the number of ice crystals to IWC is altered (see text for details) and (b) a modified version of WSM5 where the INP parameterization used (Fmod) is changed to (C) (Cooper, 1986), which predicts fewer INPs (see Sect. 5.3).

empirical relationship linking both). This, in turn, impacts the growth rate of the ice crystal mass, which depends on $N_{\mathrm{i}}$ (see Eq. 9 in Hong et al., 2004), favouring an increasing ice water content.

The transects in Fig. 5a and b clearly show the ubiquitous ice simulated with WSM5 during westerly and easterly events due to the orographic forcing, whereas the Morrison scheme leads to snow and supercooled liquid formation in both cases (Fig. 5c and d), as do the Milbrandt and Thompson schemes (not shown). As an additional experiment, we conducted a simulation over the period 6-10 January 2011 where westerlies are simulated (Fig. 5a and c). We alter the WSM5 scheme by changing the empirical relationship linking $q_{\mathrm{i}}$ to $N_{\mathrm{i}}$ as described above. We divide by 100 the resulting $N_{\mathrm{i}}$ (variable $\mathrm{xni}$ in the code where the empirical Eq. $5 \mathrm{c}$ in Hong et al. (2004) is implemented), which is diagnosed from $q_{\mathrm{i}}$ in the cloud scheme. We plot a similar transect to Fig. 5a. This results in more supercooled liquid being simulated (Fig. 11a), closer although not quite similar to what - for instance the Morrison scheme is leading to (Fig. 5c). Then, a second simulation with WSM5 was performed (Fig. 11b) by changing the INP parameterization to the one used in the Morrison scheme (more realistic, as shown in Sect. 5.3). It shows no major difference with the original simulation (Fig. 5a). The hypotheses (empirical relationships) used for the singlemoment ice crystal parameterization of WSM5 have a more determining impact on the ability to sustain supercooled water than the nature of the INP parameterization itself in the WRF schemes.

Note that a third simulation was performed with the Morrison scheme using a lower concentration of $\mathrm{CCN}$ set to $100 \mathrm{~cm}^{-3}$ (instead of $250^{-3}$ ). Using a lower CCN concentration does affect the amount of supercooled liquid formed in reducing it (not shown), but the overall distribution of liquid (the order of magnitude) remains similar, as well as the ice, thus not altering the main conclusions of this work. Note that, according to part 1 , the observed average number of drops is $100-120 \mathrm{~cm}^{-3}$ in 2010 and $150-200 \mathrm{~cm}^{-3}$ in 2011. Hence the Morrison and Thompson schemes use a drop number similar to the observed upper limit and lower limit, respectively (see Table 3). More simulations focused on particular flights (case studies) would be required to assess in greater detail the impact of the $\mathrm{CCN}$ concentration compared to the one of the INP parameterization.

Figure 12 shows the distribution of the cloud mass as a function of the temperature for the transects shown in Fig. 5 during westerlies (solid line) and easterlies (dashed line). The top row is the median simulated mass per $1{ }^{\circ} \mathrm{C}$ bin for (a) the liquid droplets, (b) the ice crystals, and (c) the snow particles. The bottom row shows the corresponding number of non-null occurrences $\left(>0.001 \mathrm{~g} \mathrm{~kg}^{-1}\right)$ over which the median values are derived in each bin.

Figure 12a shows that LWC simulated down to $-10^{\circ} \mathrm{C}$ by WSM5 is similar to Milbrandt's and Thompson's and lower than Morrison's for both easterly and westerly scenarios. However, the frequency of liquid cloud formation for WSM5 is lower by a factor of 2-4 than other schemes (Fig. 12d). At colder temperatures, WSM5's ability to simulate cloud liquid is drastically reduced for both scenarios (Fig. 12d). This could be related to the much shallower vertical extent of the WSM5-simulated cloud liquid (Fig. 7), which is limited to the warmest subfreezing temperatures. The observations show liquid clouds up to higher altitudes (Fig. 7), and the Morrison, Milbrandt, and Thompson schemes account better for the liquid at these higher altitudes (lower temperatures) than the WRF schemes. Yet these three schemes do show a decreasing trend in the supercooled liquid mass at temperatures lower than $-10^{\circ} \mathrm{C}$, despite their steady (slightly 

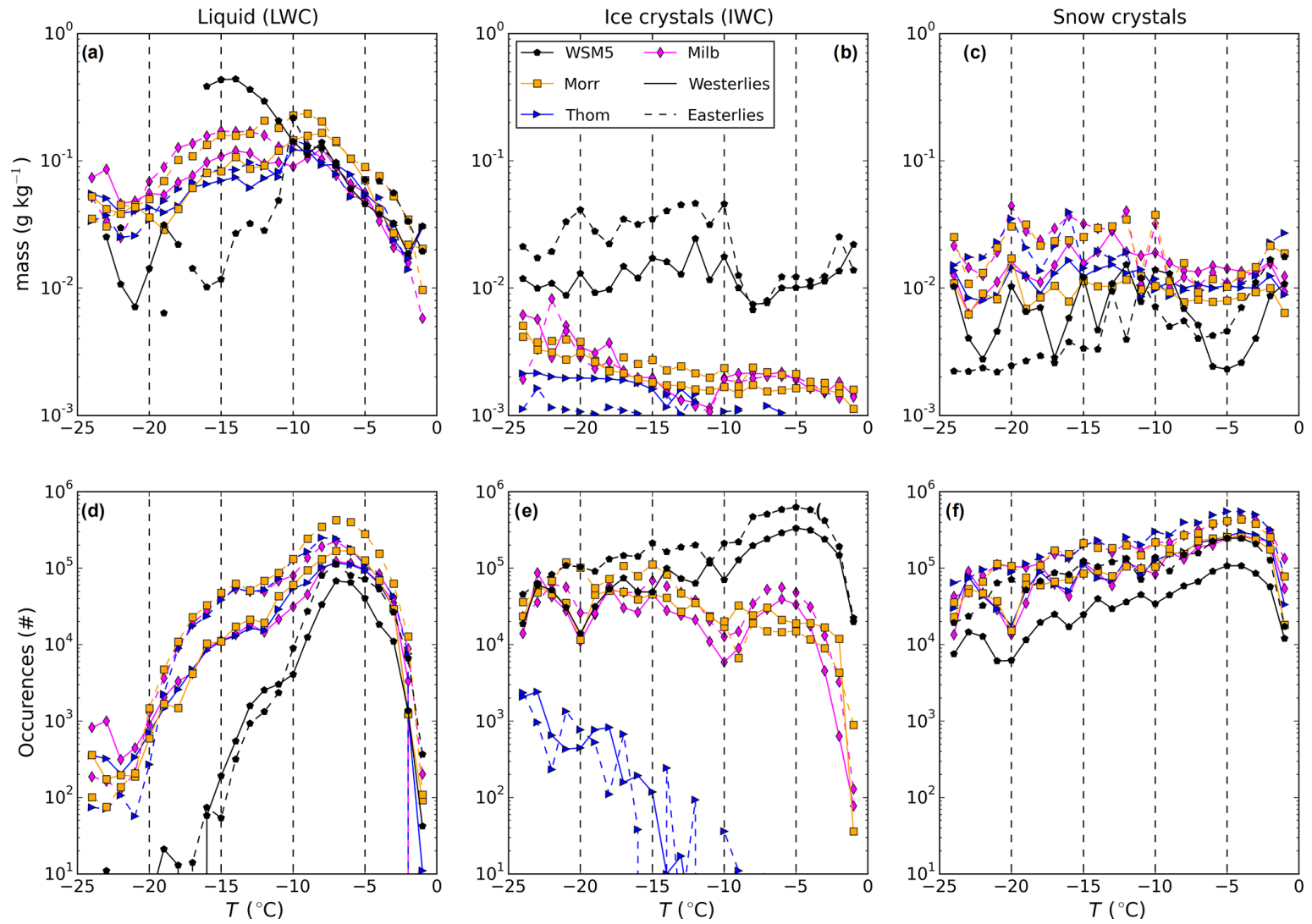

Figure 12. Distribution of (a) LWC, (b) IWC, and (c) snow crystal mass as a function of temperature (per $1^{\circ} \mathrm{C}$ bin), and the corresponding distribution of non-null occurrences of LWC, ice, and snow (d, e, f, respectively) used to derive those mass distributions for the transects shown in Fig. 5 for westerly (solid line) and easterly wind periods.

growing) ability to simulate ice and snow crystals (Fig. 12e and f). Measured vertical profiles do indeed show the presence of ice clouds at temperatures lower than $-10^{\circ} \mathrm{C}$, and the schemes simulate their occurences better than the supercooled liquid ones (not shown). Interestingly, the frequency of simulated ice crystals is the most different above $-10^{\circ} \mathrm{C}$ (Fig. 12e), where there is an order-of-magnitude difference between WSM5 and the other schemes. WSM5's IWC is a factor of 5-10 larger than for the other schemes (Fig. 12b), and this can be mainly explained by its single-moment parameterization for ice (as described above). This feature also appears in the model outputs at stations AWS14 (Fig. 3) and AWS15 (not shown), where the WRF schemes simulate 34 times more cloud ice crystal mass than the other cloud schemes.

Overall the Morrison, Thompson, and Milbrandt schemes are better able than the WRF schemes to form supercooled liquid in both years on both sides of the peninsula. They perform better in simulating liquid cloud occurrences, and the Morrison scheme gives an average LWC closer to the measured value, except in the east in 2011, when it overestimates the liquid content (Sect. 4.3.1, Fig. 6b and d). However, the observed interannual variations of the LWC from 2010 to
2011 east of the peninsula (Fig. 6), and described as statistically significant in part 1, are not captured by any of the cloud schemes. Part 1 reported on the role of the nature and number of aerosols, of which a subset act as CCN or INPs. Based on part 1, it is likely that the observed regional and interannual cloud microphysics variabilities need an adequate aerosol model in order to be properly simulated. The clouds measured by the aircraft campaigns were exclusively mixedphase clouds, and Table 6 shows that at least down to $-13^{\circ} \mathrm{C}$ the Morrison and Milbrandt schemes are more capable of simulating the observed relative proportions of liquid and ice across this temperature range. However, as shown by Fig. 7 little supercooled liquid is simulated above $1500 \mathrm{~m}$ along the flight tracks.

The poorer performances of the schemes to the west of the peninsula can be seen in the poorer ability to predict the occurrences of both cloud liquid (Fig. 6a and c) and cloud ice (Fig. 9a and c) in that region. The tracks predicted with some liquid phase comprise about $20 \%$ (2010) or $40 \%$ (2011) of the total observed. Figure 9a and c show a slightly better ability to predict the ice phase, but still less than $50 \%$ of the tracks are predicted. The associated failure of any scheme to lower the LW surface radiation biases at 
Rothera Research Station (Table 4) suggests an overall inability to correctly simulate liquid clouds where they are observed. As noted in Sect. 4.4, the average temperature biases are larger to the west of the peninsula than to the east of the peninsula, by 1 to $2^{\circ} \mathrm{C}$ (Fig. 10a). On both sides the average temperature is overestimated. Since the supersaturation depends exponentially on the temperature, the lowest ability of the schemes to predict liquid cloud formation to the west is consistent with the larger temperature biases measured in that region. The warmer oceanic and sea-ice-free influence of the western Peninsula implies more convective processes (compared to the east) that are badly resolved at $5 \mathrm{~km}$ resolution and may also prevent better matching with the aircraft observations. The $5 \mathrm{~km}$ horizontal resolution lies in the socalled "grey zone" (resolution 1-10 km), where convective processes are badly simulated and parameterized. An additional explanation for the bad performances of the schemes above Rothera Research Station may be the complex topography as shown in Fig. 5. The station is situated in the eastern part of Adelaide Island and is surrounded by mountainous features. More generally these features will also affect the air flow reaching the regions where the flights took place, to the west of the peninsula. By contrast, the eastern part of the peninsula with the Larsen C Ice Shelf has much less complex topographical features, and this should help the modelling of the clouds on that side.

Finally, it is worth recalling that working with ice categories, as well as different definitions for these ice categories from on scheme to another, makes overall comparisons to flight measurements difficult. The Thompson scheme shows very little formation of ice crystals, which are readily converted to snow crystals (Fig. 12f). Every cloud scheme defines a radius cut-off between ice crystals and snow crystals ranging between 100 and $250 \mu \mathrm{m}$ (Table 3), with Thompson having the second-largest value at $200 \mu \mathrm{m}$. It is not clear why the Thompson scheme's cloud ice crystal numbers are so low (Figs. 6, and 12b). The Thompson scheme gives much less frequent and much less abundant crystals at radii below $200 \mu \mathrm{m}$ (Fig. 12e) than the ones above that radius (Fig. 12f), and this is at odds with the other schemes and with the observations. Finally, given that the observations show an average crystal radius of $150-250 \mu \mathrm{m}$ in 2010 and $200-250 \mu \mathrm{m}$ in 2011 (not shown), this is probably not ideal for working with cloud schemes having an ice-snow radius cut-off artificially set around those sizes.

\subsection{The INP parameterizations}

All the cloud microphysics schemes investigated in this work rely on INP parameterizations to initiate the ice phase, and here we comment on those. The number concentration of INPs is diagnosed from the modelled atmospheric temperature only. These empirical parameterizations address the different ice nucleation mechanisms (see Introduction). They are triggered at different temperatures or supersaturation thresholds, depending on the cloud scheme (Table 3). They increase exponentially with decreasing temperatures and can lead to very different INPs concentrations as illustrated in Fig. 13a (coloured lines). This figure also shows the two peaks in the measured ice crystal distribution around $-20^{\circ} \mathrm{C}$ and $-5^{\circ} \mathrm{C}$. The former relates to primary ice production (accounted for by the INP parameterizations), while the latter relates to a secondary ice production process identified as the Hallett-Mossop process (Hallett and Mossop, 1974) in part 1.

The direct consequence of the use of different INP parameterizations is clear differences between icy hydrometeor number concentrations as a function of temperature. To illustrate this, Fig. 13b shows the median non-null number concentration of total icy condensates (ice crystals, snow and graupel particles) over the transects shown in Fig. 5 for both the westerly (solid lines) and easterly (dashed lines) cases. For deposition/condensation freezing (which does not require the presence of supercooled droplets) the Milbrandt scheme uses the INP parameterization from Meyers et al. (1992) (their Eq. 2.4), while Morrison and Thompson use the one from Cooper (1986). These parameterizations are now referred to as (M) and (C), respectively (Table 3). This translates into the drastically different number concentrations at temperatures above $-15^{\circ} \mathrm{C}$ (Fig. 13b), because INP concentrations predicted by (M) (Fig. 13a, purple lines) are much larger than the ones predicted by (C) (blue line). For contact freezing, the Milbrandt and Morrison schemes use the INP parameterization from Meyers et al. (1992) (their Eq. 2.6), which is referred to as ( $\left.\mathrm{M}^{\prime}\right)$ in Table 3. The Thompson scheme does not explicitly parameterize contact freezing. The consequence is that the Morrison scheme predicts larger amount of icy condensates than the Thompson scheme since $\left(\mathrm{M}^{\prime}\right)$ predicts much larger INP concentrations than (C). The latter effect is enhanced by the more constraining thresholds on temperature and ice supersaturation for the Thompson scheme to allow for ice formation (Table 3). The Milbrandt scheme relies on the INP parameterization (M), which predicts much larger amounts of INPs in the deposition mode, which does not depend on the scheme's ability to simulate supercooled liquid water in the first place. Interestingly, the Milbrandt scheme has an average solid-water content $\left(\mathrm{SWC}_{0}\right.$, and SWC) almost twice as big as the Morrison and Thompson schemes (Fig. 4b and d, respectively).

Note that the Hallett-Mossop process is implemented in the Morrison, Thompson, and Milbrandt schemes, after Reisner et al. (1998). A similar plot to Fig. 13a suggests that the process is triggered in the model around $-5^{\circ} \mathrm{C}$ along the flight tracks in the simulations, at least for the Thompson scheme (not shown). However, higher-resolution simulations and case studies are needed to investigate in detail the contribution of this mechanism in the different cloud schemes; this is beyond the scope of the present work.

DeMott et al. (2010) developed an INP parameterization (hereafter called DeMott) using both the temperature and the 

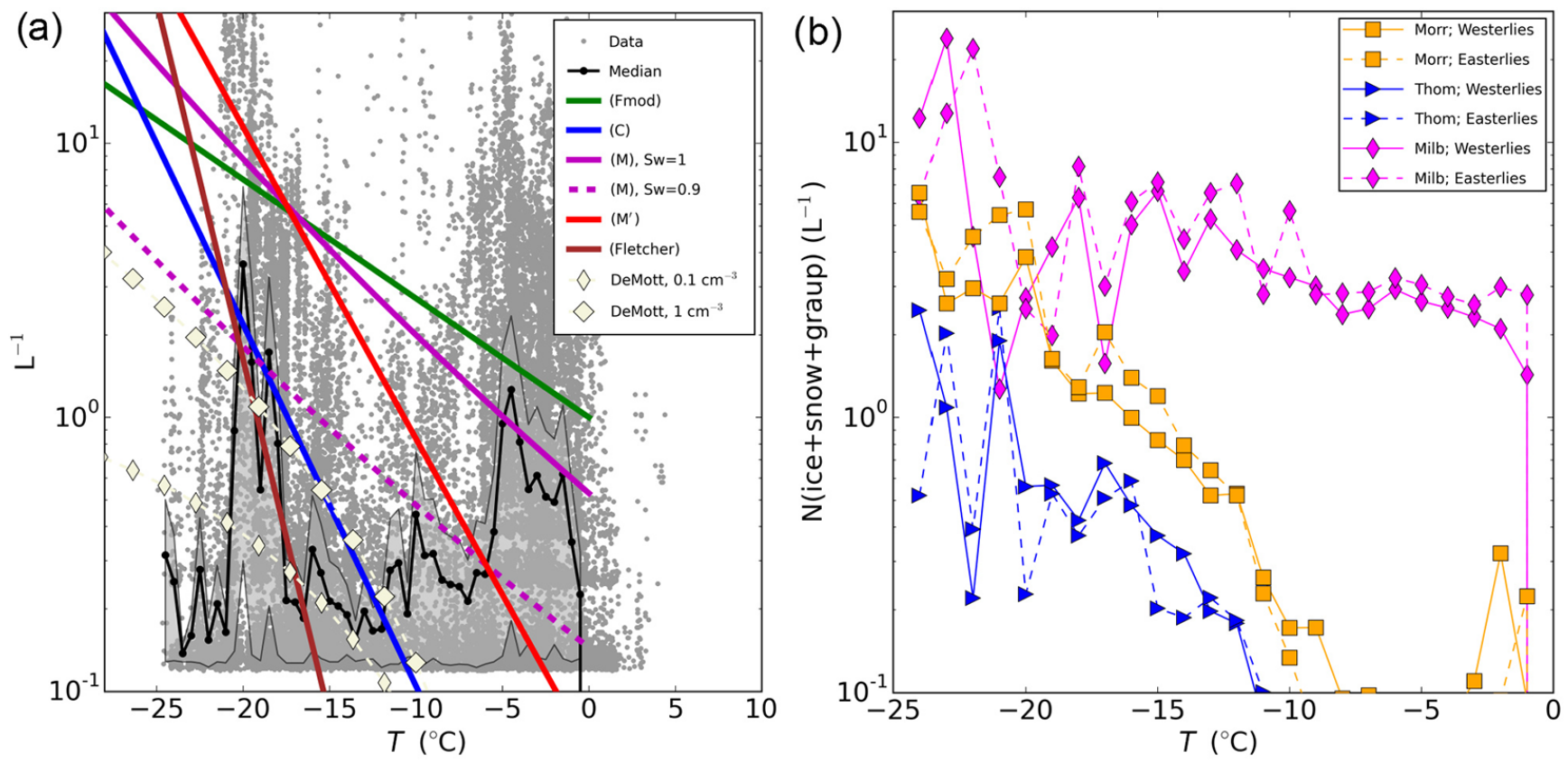

Figure 13. (a) Ice crystal measurement data points as a function of the temperature (grey) with their median per $0.5^{\circ} \mathrm{C}$ bins (black solid line), along with the absolute median deviation in shaded grey. The labelled INP parameterizations used by the different cloud schemes (Table 3 ) are overplotted. DeMott refers to the DeMott et al. (2010) INP parameterization (see text for details). (b) Same as panel (a) but for the median of the total number concentrations of icy hydrometeors in the same transects used in Fig. 5 for both cases: the westerly case (solid lines) and the easterly case (dashed lines).

observed aerosol number concentration for aerosols larger than $0.5 \mu \mathrm{m}$ in diameter (as presented in part 1), believed to be the main contributors to the worldwide INP population (DeMott et al., 2010). Aircraft measurements used in part 1 made it possible to derive out-of-cloud aerosol concentration for diameters larger than $0.5 \mu \mathrm{m}$. Using this information to describe the aerosol background, we compared the measured total ice crystal number concentrations to INP predictions by DeMott and to the other INP parameterizations implemented in the WRF cloud schemes. The comparison to the observations was done at temperatures below $-9{ }^{\circ} \mathrm{C}$, as this is the temperature range over which DeMott parameterization was derived. This also allows the warmer temperatures to be discarded where the Hallett-Mossop process was identified as responsible for the ice crystal production around $-5^{\circ} \mathrm{C}$ (see part 1). The INP parameterizations are meant to account only for the primary ice production process.

For each measurement of crystals below $-9^{\circ} \mathrm{C}$ (one data point every second), a corresponding number of INPs is derived for each parameterization using the measured temperature. For the background aerosol input to the DeMott parameterization, we derived a $1 \mathrm{~min}$ averaged out-of-cloud aerosol number concentration $\left(n_{\text {aer }}\right)$ within $\pm 30 \mathrm{~s}$ of any crystal measurement. As shown in part 1 (see their Fig. 13) the average $n_{\text {aer }}$ ranges between 0.1 and $1 \mathrm{~cm}^{-3}$. Figure 13a shows the DeMott parameterization for those two values (white diamond-shaped markers). We computed flight averages for the observations and for each INP parameterization. Figure 14 shows the observed and predicted average values for both years. Table 7 gives the median relative difference $(\epsilon)$ between flight-averaged observations (Obs) and the INP parameterizations predictions (INPparam), along with the associated median absolute deviation $(\Delta \epsilon)$.

The DeMott parameterization performs better than any other INP parameterization as suggested by Fig. 14a and $b$. Table 7 shows that DeMott $(\epsilon=0.5-0.6)$ performs better than Cooper (C) $(\epsilon=1.6-2)$ (used by the Morrison and Thompson schemes). This is because of its ability to take into account the number concentration of aerosols. For instance if we force a constant value of $n_{\text {aer }}=1 \mathrm{~cm}^{-3}$, the DeMott parameterization performs as poorly as (C) and worse than the original Fletcher (as opposed to Fmod used by Hong et al., 2004, see their Eq. 8). However, if we force $n_{\text {aer }}=0.1 \mathrm{~cm}^{-3}$ (the average $n_{\text {aer }}$ across the Antarctic Peninsula above $2000 \mathrm{~m}$, where most primary ice production occurs; see part 1 and their Figs. 13 and 14), then DeMott performs better than (C) or any other parameterization. It performs as well as DeMott with a varying $n_{\text {aer }}$ (compare the two first lines of Table 7). The modified version of Fletcher (Fmod) used in WSM5 is the worst performer $(\epsilon>20)$, followed by the Meyer (M) parameterization, which is used by the Milbrandt scheme $(\epsilon=4.5-24$ for relative humidities characteristics of mixedphase clouds, $90-100 \%$ ). 

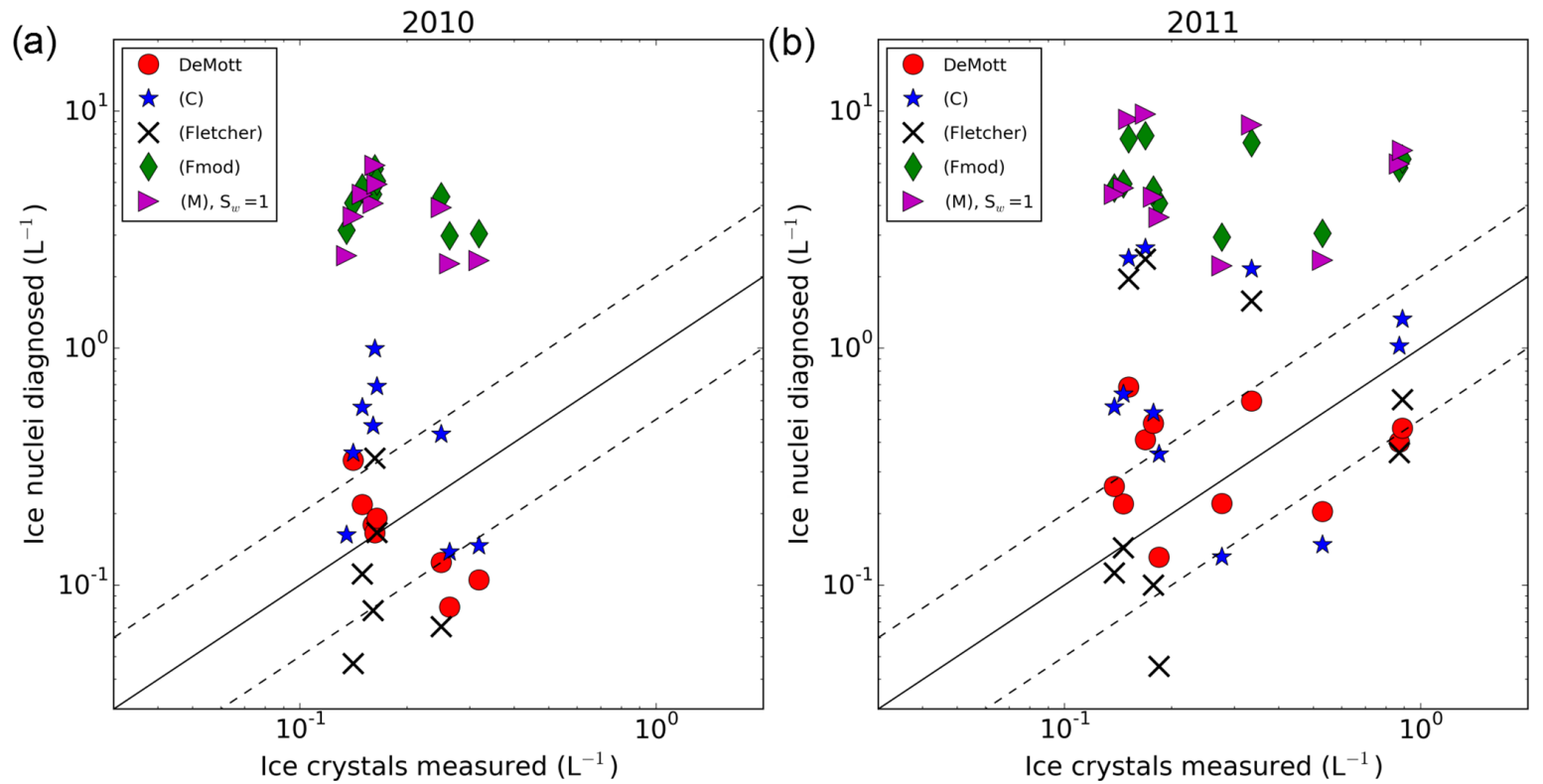

Figure 14. Predicted INP number densities versus observed number densities of crystals (flights averages) for various INP parameterizations for (a) 2010 and (b) 2011. The solid lines correspond to the one-to-one line, and the dashed lines corresponds to a factor-of-2 difference between the $y$ and $x$ axes. See Table 3 for the references of the various INP parameterizations.

Table 7. The median of the flight-averaged $\epsilon=\mid$ INPparam Obs $\mid$ /Obs, and the corresponding median absolute deviation for different INP parameterizations, for the two different years. DeMott refers to DeMott et al. (2010), and Fletcher to Fletcher (1962); see Table 3 for the other references.

\begin{tabular}{lrr|rr}
\hline & \multicolumn{2}{c|}{2010} & \multicolumn{2}{c}{2011} \\
\cline { 2 - 5 } & $\epsilon$ & $\Delta \epsilon$ & $\epsilon$ & $\Delta \epsilon$ \\
\hline DeMott, variable $n_{\text {aer }}$ & 0.48 & 0.26 & 0.61 & 0.27 \\
DeMott, $n_{\text {aer }}=0.1$ & 0.42 & 0.21 & 0.65 & 0.18 \\
DeMott, $n_{\text {aer }}=1$ & 1.82 & 1.04 & 1.98 & 1.33 \\
Fletcher & 0.73 & 0.24 & 0.75 & 0.43 \\
$($ Fmod $)$ & 26.7 & 4.50 & 21.10 & 12.16 \\
$(\mathrm{C})$ & 1.56 & 1.08 & 2.00 & 1.47 \\
$(\mathrm{M}), S_{\mathrm{W}}=1$ & 24.35 & 7.21 & 23.35 & 16.32 \\
$(\mathrm{M}), S_{\mathrm{W}}=0.9$ & 4.65 & 1.40 & 4.38 & 3.48 \\
\hline
\end{tabular}

It should be recalled that the DeMott parameterization is based on analysis of aerosols, which exclude strong marine influence, and so sea salts were not included (DeMott et al., 2010). Also, aerosol concentrations below $0.3 \mathrm{~cm}^{-3}$ have less weight in the DeMott parameterization's analytical derivation than the larger values $\left(0.5-5 \mathrm{~cm}^{-3}\right)$, as shown by Fig. S1 in the supplementary materials of DeMott et al. (2010). Despite these caveats, the strength of the DeMott parameterization is to be able to account for the low aerosol number densities at altitudes higher than $2000 \mathrm{~m}$, where primary ice production occurs on the Antarctic Peninsula (part 1). This makes it, on average, a better candidate than any other IN parameterizations for future work meant to improve the cloud microphysics scheme for Antarctic clouds.

Finally, note that the comparisons are made in times and places where ice crystals were indeed measured, ignoring instances where cloud ice was not measured, but where any INP parameterization would still predict some crystal production. This challenging issue could probably be dealt with only in managing the coupling of the cloud scheme to an aerosol model able to predict the absence of INPs. Moreover, given existing biases in water vapour and temperature along each flight track separately (as opposed to the averages discussed in Sect. 4.4), better calibrating the INP parameterization consists of only one of the needed improvements for Antarctic cloud modelling, as discussed below.

\subsection{Additional results on water vapour and temperature biases, and cloud nuclei parameterizations}

In Sect. 4.4 it was shown that the model was able to capture the average temperature within $0.5-2.5^{\circ} \mathrm{C}$ and the average water vapour within $0.3-0.7 \mathrm{~g} \mathrm{~kg}^{-1}$. The average simulated temperature and water vapour are within the variability (standard deviation within each longitude bin) of the observations. Although the average behaviour of the model matches the average observations, it should be noted that water vapour and temperature biases do hamper the good prediction of the clouds by the model. As an example, Fig. 15a shows the time series of the water vapour, and of the temperature, as measured (black line) and as simulated when using the Morrison scheme (red line) for flight 150 . The model fails in simulating 
(a)
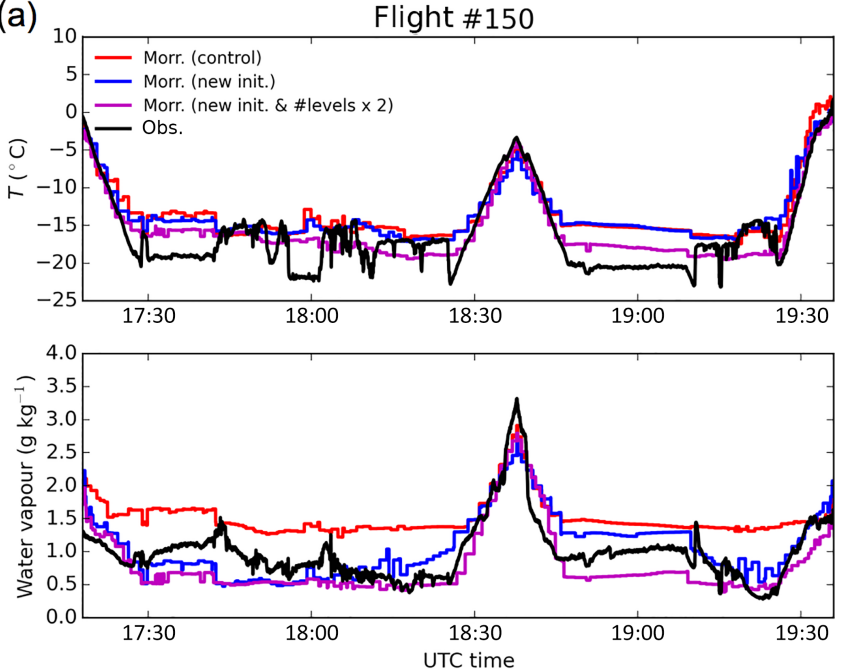

(b)
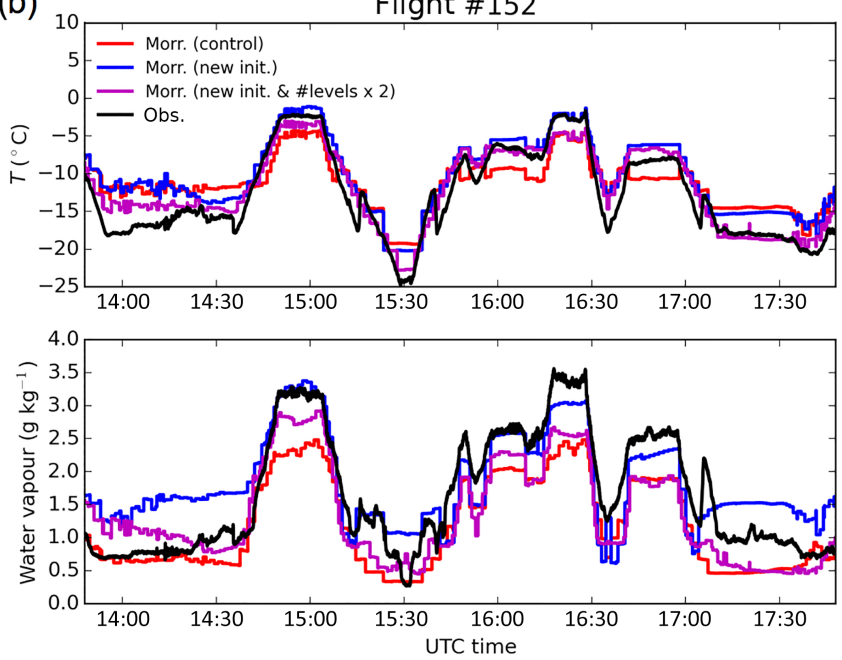

Figure 15. Time series of water vapour $\left(\mathrm{g} \mathrm{kg}^{-1}\right)$ and temperature $\left({ }^{\circ} \mathrm{C}\right)$ measured during (a) flight 150 and (b) flight 152. For panels (a) and (b), the observation is the black solid line. Simulation outputs are overplotted: the simulations used to derive the averages presented in this work (red line), a different simulation over the period 11-20 January 2011 (thus with an initialization closer to the date of the measurements)(blue solid line), and the latter simulation with - additionally - a doubling of the number of vertical levels ( 60 instead of 30) (magenta solid line).

the liquid cloud before 18:30 UTC and after 18:42 UTC (not shown), where the water vapour and temperature biases are the largest (see the red solid line in Fig. 15a), while it does simulate liquid cloud (not shown) where the bias is much reduced (at warmer temperatures, lower altitudes) between those two times (red solid line, in Fig. 15a).

An additional simulation was performed over the period 11-20 January 2011 using the Morrison scheme, initializing it 10 days later than the simulations used so far (on 11 January instead of starting on 1 January). During this period, four flights took place (150-153), and we show flights 150 and 152 (Fig. 15). The result is shown as the blue solid line in Fig. 15a and b. The initialization of the model closer to the dates of the airborne measurements does lead to a lower bias in water vapour for both flights. However, the bias in terms of temperature is relatively less reduced across the flights, suggesting that the initialization date of the model has a greater impact on the quality of the water vapour prediction. However the improvement in terms of water vapour does not lead to an improvement of the liquid cloud prediction along the flight tracks, and it even leads to the suppression of the liquid cloud initially simulated along flight 152 's flight tracks (not shown). Note that further doubling the number of vertical levels for the above shorter simulation (using 60 levels, instead of 30 levels) leads to a very limited further reduction of the water vapour bias over the four flights, while it does reduce the temperature bias over the flights (magenta solid line in Fig. 15a and b). Overall, those results suggest that initializing the model at a closer date to the observations reduces on average the water vapour bias, while doubling the number of levels helps reduce the temperature bias. However, this improvement is not systematic along the flights and not significant enough to really impact the cloud prediction, at least in the investigated cases.

Another run was performed over the same period of the four flights, this time only replacing the INP parameterization used in the Morrison scheme (see Sect. 5.3) with the DeMott parameterization. The result was a much reduced ice crystal water content during the flights (actually lowering the quality of the ice phase prediction; not shown), but no improvement was obtained for the supercooled liquid, which may be explained by the remaining water vapour and temperature biases (not shown) preventing supersaturation with respect to liquid water from being simulated.

This discussion stresses the need for further work investigating the water vapour and temperature biases in addition to using appropriate cloud scheme (double-moment scheme for the ice crystals) and INP parameterization for improving Antarctic cloud simulation.

\section{Summary and perspective}

In this work we provide the first intercomparison of WRF microphysics scheme performances in Antarctica over the Antarctic Peninsula within Polar WRF at $5 \mathrm{~km}$ resolution, as well as the first comparisons with in situ cloud measurements on both sides of the peninsula. The specificities and properties of the schemes are summarized in Tables 2 and 3 . We compared the simulations to averaged aircraft measurements of cloud microphysics properties (part 1) as well as other atmospheric properties on both sides of the peninsula and over the two periods of interest (February 2010 and January 2011). This paper was motivated by King et al. (2015), which pointed towards possible problems in the thermodynamic phase simulation in three high-resolution models at 
$5 \mathrm{~km}$ resolution over the Larsen $\mathrm{C}$ Ice Shelf on the eastern side of the peninsula, as well as Bromwich et al. (2013a), which demonstrated the presence of Antarctica-wide surface radiative biases within Polar WRF at coarser $(60-15 \mathrm{~km})$ resolution. This study is a first step towards the improvement of cloud modelling and operational forecast, with Polar WRF and AMPS, respectively.

The main results are as follows.

- The surface longwave radiative bias is significantly reduced over the Larsen C Ice Shelf when using the Morrison, Thompson, and Milbrandt schemes, compared to WSM5 or WDM6.

- Importantly, the Morrison, Thompson, and Milbrandt schemes are also the schemes that lead to better agreement with aircraft cloud measurements (occurrences of the liquid and ice phase, as well as values of the cloud mass mixing ratio) than WSM5 and WDM6.

- The Morrison, Thompson, and Milbrandt schemes perform better than the WSM5 and WDM6 schemes because of their double-moment parameterization for the ice phase. The latter are single-moment schemes for the ice crystals. A realistic ice parameterization is essential to the simulation of supercooled liquid.

- The DeMott parameterization (DeMott et al., 2010), which is not currently implemented in any of the WRF microphysics schemes, better accounts for the ice crystal number densities measured during both campaigns when using as input the typical concentrations of outof-cloud aerosols measured above $2000 \mathrm{~m}$, where primary ice production occurs (see part 1). However, the INPs alone cannot improve the simulation of the observed clouds.

- The model can simulate the average water vapour and temperature distribution across the peninsula; however biases in both fields can still explain the failure in simulating clouds when looking at specific flights (as opposed to the average fields). Moreover, larger bias in temperatures to the west of the peninsula can explain the lesser ability of the simulations to reproduce the observed clouds.

- As WSM5 is the scheme used in the Antarctic Mesoscale Prediction System, the present work provides new results promoting the improvement of the current cloud scheme implementation in the operational model.

Future work will look at case studies focusing on specific flights at higher spatial and vertical resolution. This will also make use of the latest campaign for measuring Antarctic clouds in the eastern Weddell Sea in NovemberDecember 2015 (O'Shea et al., 2017). More investigation of the impact of smaller (temporal or spatial) scale temperature and water vapour biases on mixed-phase clouds simulation will be needed. Often disregarded in simulation work performed over Antarctica not related to cloud studies, cloud schemes should be more systematically considered. Investigating Antarctic clouds and their impact on the energy budget is an important step to help quantify the role of atmospherically driven processes in the evolution of the ice shelves, the glaciers, and the Antarctic ice mass balance, and importantly to improve the forecast for field operations.

Data availability. The data are being formatted for inclusion in the Polar Data Centre and will be available soon.

Competing interests. The authors declare that they have no conflict of interest.

Acknowledgements. The authors thank the editor and two anonymous reviewers, who helped to improve the presentation and the content of the manuscript. The authors thank Tony Phillips and Pranab Deb for providing the Antarctic topography adapted to WRF and derived from Fretwell et al. (2013). The study was funded by the Natural Environment Research Council (NERC) under grant NE/K01305X/1. Constantino Listowski also thanks CNES for postdoctoral fellowship funding.

Edited by: Martina Krämer

Reviewed by: two anonymous referees

\section{References}

Baumgardner, D., Jonsson, H., Dawson, W., O'Connor, D., and Newton, R.: The cloud, aerosol and precipitation spectrometer: a new instrument for cloud investigations, Atmos. Res., 59-60, 251-264, https://doi.org/10.1016/s0169-8095(01)00119$3,2001$.

Bigg, E. K.: The Supercooling of Water, P. Phys. Soc. Lond. B, 66, 688-694, https://doi.org/10.1088/0370-1301/66/8/309, 1953.

Boucher, O., Randall, D., Artaxo, P., Bretherton, C., Feingold, G., Forster, P., Kerminen, V.-M., Kondo, Y., Liao, H., Lohmann, U., Rasch, P., Satheesh, S., Sherwood, S., Stevens, B., and Zhang, X.: Clouds and Aerosols, in: Climate Change 2013: The Physical Science Basis. Contribution of Working Group I to the Fifth Assessment Report of the Intergovernmental Panel on Climate Change, edited by: Stocker, T. F., Qin, D., Plattner, G.-K., Tignor, M., Allen, S. K., Boschung, J., Nauels, A., Xia, Y., Bex, V., and Midgley, P. M., Cambridge University Press, Cambridge, UK and New York, NY, USA, 2013.

Bromwich, D. H., Nicolas, J. P., Hines, K. M., Kay, J. E., Key, E. L., Lazzara, M. A., Lubin, D., McFarquhar, G. M., Gorodetskaya, I. V., Grosvenor, D. P., Lachlan-Cope, T., and van Lipzig, N. P. M.: Tropospheric clouds in Antarctica, Rev. Geophys., 50, RG1004, https://doi.org/10.1029/2011RG000363, 2012. 
Bromwich, D. H., Otieno, F. O., Hines, K. M., Manning, K. W., and Shilo, E.: Comprehensive evaluation of polar weather research and forecasting model performance in the Antarctic, J. Geophys. Res.-Atmos., 118, 274-292, https://doi.org/10.1029/2012jd018139, 2013a.

Bromwich, D. H., Nicolas, J. P., Monaghan, A. J., Lazzara, M. A., Keller, L. M., Weidner, G. A., and Wilson, A. B.: Central West Antarctica among the most rapidly warming regions on Earth, Nat. Geosci., 6, 139-145, https://doi.org/10.1038/ngeo1671, 2013b.

Brown, P. R. A. and Francis, P. N.: Improved Measurements of the Ice Water Content in Cirrus Using a Total-Water Probe, J. Atmos. Ocean. Tech., 12, 410-414, https://doi.org/10.1175/15200426(1995)012<0410:imotiw>2.0.co;2, 1995.

Burrows, S. M., Hoose, C., Pöschl, U., and Lawrence, M. G.: Ice nuclei in marine air: biogenic particles or dust?, Atmos. Chem. Phys., 13, 245-267, https://doi.org/10.5194/acp-13-2452013, 2013.

Chou, M.-D. and Suarez, M. J.: A solar radiation parameterization for atmospheric studies, Tech. rep., NASA/TM-1999-104606, vol. 15, edited by: Suarez, M. J., National Aeronautics and Space Administration, Goddard Space Flight Center, Greenbelt, Maryland, USA, 1999.

Cohard, J.-M. and Pinty, J.-P.: A comprehensive twomoment warm microphysical bulk scheme. I: Description and tests, Q. J. Roy. Meteor. Soc., 126, 1815-1842, https://doi.org/10.1002/qj.49712656613, 2000.

Cooper, W. A.: Ice Initiation in Natural Clouds, Meteor. Mon., 21, 29-32, https://doi.org/10.1175/0065-9401-21.43.29, 1986.

Deb, P., Orr, A., Hosking, J. S., Phillips, T., Turner, J., Bannister, D., Pope, J. O., and Colwell, S.: An assessment of the Polar Weather Research and Forecasting (WRF) model representation of near-surface meteorological variables over West Antarctica, J. Geophys. Res.-Atmos., 121, 1532-1548, https://doi.org/10.1002/2015jd024037, 2016.

Dee, D. P., Uppala, S. M., Simmons, A. J., Berrisford, P., Poli, P., Kobayashi, S., Andrae, U., Balmaseda, M. A., Balsamo, G., Bauer, P., Bechtold, P., Beljaars, A. C. M., van de Berg, L., Bidlot, J., Bormann, N., Delsol, C., Dragani, R., Fuentes, M., Geer, A. J., Haimberger, L., Healy, S. B., Hersbach, H., Hólm, E. V., Isaksen, L., Kållberg, P., Köhler, M., Matricardi, M., McNally, A. P., Monge-Sanz, B. M., Morcrette, J.-J., Park, B.-K., Peubey, C., de Rosnay, P., Tavolato, C., Thépaut, J.-N., and Vitart, F.: The ERA-Interim reanalysis: configuration and performance of the data assimilation system, Q. J. Roy. Meteor. Soc., 137, 553-597, https://doi.org/10.1002/qj.828, 2011.

Demott, P. J., Meyers, M. P., and Cotton, W. R.: Parameterization and Impact of Ice initiation Processes Relevant to Numerical Model Simulations of Cirrus Clouds, J. Atmos. Sci., 51, 77-90, https://doi.org/10.1175/15200469(1994)051<0077:PAIOII>2.0.CO;2, 1994.

DeMott, P. J., Prenni, A. J., Liu, X., Kreidenweis, S. M., Petters, M. D., Twohy, C. H., Richardson, M. S., Eidhammer, T., and Rogers, D. C.: Predicting global atmospheric ice nuclei distributions and their impacts on climate, P. Natl. Acad. Sci. USA, 107, 11217-11222, https://doi.org/10.1073/pnas.0910818107, 2010.

Flato, G., Marotzke, J., Abiodun, B., Braconnot, P., Chou, S., Collins, W., Cox, P., Driouech, F., Emori, S., Eyring, V., Forest, C., Gleckler, P., Guilyardi, E., Jakob, C., Kattsov, V., Reason, C., and Rummukainen, M.: Evaluation of Climate Models, in: Climate Change 2013: The Physical Science Basis. Contribution of Working Group I to the Fifth Assessment Report of the Intergovernmental Panel on Climate Change, edited by: Stocker, T. F., Qin, D., Plattner, G.-K., Tignor, M., Allen, S. K., Boschung, J., Nauels, A., Xia, Y., Bex, V., and Midgley, P. M., Cambridge University Press, Cambridge, UK and New York, NY, USA, 2013.

Fletcher, N. H.: The Physics of Rainclouds, Cambridge University Press, Cambridge, UK, 1962.

Fretwell, P., Pritchard, H. D., Vaughan, D. G., Bamber, J. L., Barrand, N. E., Bell, R., Bianchi, C., Bingham, R. G., Blankenship, D. D., Casassa, G., Catania, G., Callens, D., Conway, H., Cook, A. J., Corr, H. F. J., Damaske, D., Damm, V., Ferraccioli, F., Forsberg, R., Fujita, S., Gim, Y., Gogineni, P., Griggs, J. A., Hindmarsh, R. C. A., Holmlund, P., Holt, J. W., Jacobel, R. W., Jenkins, A., Jokat, W., Jordan, T., King, E. C., Kohler, J., Krabill, W., Riger-Kusk, M., Langley, K. A., Leitchenkov, G., Leuschen, C., Luyendyk, B. P., Matsuoka, K., Mouginot, J., Nitsche, F. O., Nogi, Y., Nost, O. A., Popov, S. V., Rignot, E., Rippin, D. M., Rivera, A., Roberts, J., Ross, N., Siegert, M. J., Smith, A. M., Steinhage, D., Studinger, M., Sun, B., Tinto, B. K., Welch, B. C., Wilson, D., Young, D. A., Xiangbin, C., and Zirizzotti, A.: Bedmap2: improved ice bed, surface and thickness datasets for Antarctica, The Cryosphere, 7, 375-393, https://doi.org/10.5194/tc-7-375-2013, 2013.

Gorodetskaya, I. V., Kneifel, S., Maahn, M., Van Tricht, K., Thiery, W., Schween, J. H., Mangold, A., Crewell, S., and Van Lipzig, N. P. M.: Cloud and precipitation properties from ground-based remote-sensing instruments in East Antarctica, The Cryosphere, 9, 285-304, https://doi.org/10.5194/tc-9-285-2015, 2015.

Grosvenor, D. P., Choularton, T. W., Lachlan-Cope, T., Gallagher, M. W., Crosier, J., Bower, K. N., Ladkin, R. S., and Dorsey, J. R.: In-situ aircraft observations of ice concentrations within clouds over the Antarctic Peninsula and Larsen Ice Shelf, Atmos. Chem. Phys., 12, 11275-11294, https://doi.org/10.5194/acp-12-112752012, 2012.

Hallett, J. and Mossop, S. C.: Production of secondary ice particles during the riming process, Nature, 249, 26-28, https://doi.org/10.1038/249026a0, 1974.

Harig, C. and Simons, F. J.: Accelerated West Antarctic ice mass loss continues to outpace East Antarctic gains, Earth Planet. Sc. Lett., 415, 134-141, https://doi.org/10.1016/j.eps1.2015.01.029, 2015.

Herbert, R. J., Murray, B. J., Dobbie, S. J., and Koop, T.: Sensitivity of liquid clouds to homogenous freezing parameterizations, Geophys. Res. Lett., 42, 1599-1605, https://doi.org/10.1002/2014g1062729, 2015.

Hines, K. M. and Bromwich, D. H.: Development and Testing of Polar Weather Research and Forecasting (WRF) Model. Part I: Greenland Ice Sheet Meteorology, Mon. Weather Rev., 136, 1971-1989, https://doi.org/10.1175/2007mwr2112.1, 2008.

Hong, S.-Y., Dudhia, J., and Chen, S.-H.: A Revised Approach to Ice Microphysical Processes for the Bulk Parameterization of Clouds and Precipitation, Mon. Weather Rev., 132, 103-120, https://doi.org/10.1175/15200493(2004)132<0103:ARATIM>2.0.CO;2, 2004.

Hoose, C. and Möhler, O.: Heterogeneous ice nucleation on atmospheric aerosols: a review of results from labo- 
ratory experiments, Atmos. Chem. Phys., 12, 9817-9854, https://doi.org/10.5194/acp-12-9817-2012, 2012.

Igel, A. L., Igel, M. R., and van den Heever, S. C.: Make It a Double? Sobering Results from Simulations Using SingleMoment Microphysics Schemes, J. Atmos. Sci., 72, 910-925, https://doi.org/10.1175/jas-d-14-0107.1, 2015.

Khairoutdinov, M. and Kogan, Y.: A New Cloud Physics Parameterization in a Large-Eddy Simulation Model of Marine Stratocumulus, Mon. Weather Rev., $\quad 128, \quad 229-243$, https://doi.org/10.1175/15200493(2000)128<0229:ANCPPI>2.0.CO;2, 2000.

King, J. C. and Turner, J.: Antarctic Meteorology and Climatology (Cambridge Atmospheric and Space Science Series), Cambridge University Press, Cambridge, UK, 1997.

King, J. C., Lachlan-Cope, T. A., Ladkin, R. S., and Weiss, A.: Airborne Measurements in the Stable Boundary Layer over the Larsen Ice Shelf, Antarctica, Bound.-Lay. Meteorol., 127, 413428, https://doi.org/10.1007/s10546-008-9271-4, 2008.

King, J. C., Gadian, A., Kirchgaessner, A., Kuipers Munneke, P., Lachlan-Cope, T. A., Orr, A., Reijmer, C., van den Broeke, M. R., van Wessem, J. M., and Weeks, M.: Validation of the summertime surface energy budget of Larsen C Ice Shelf (Antarctica) as represented in three high-resolution atmospheric models, J. Geophys. Res.-Atmos., 120, 1335-1347, https://doi.org/10.1002/2014JD022604, 2015.

Lachlan-Cope, T.: Antarctic clouds, National Institute Polar Research Memoirs, 29, 150-158, https://doi.org/10.1111/j.17518369.2010.00148.x, 2010.

Lachlan-Cope, T., Listowski, C., and O'Shea, S.: The microphysics of clouds over the Antarctic Peninsula - Part 1: Observations, Atmos. Chem. Phys., 16, 15605-15617, https://doi.org/10.5194/acp-16-15605-2016, 2016.

Lawson, R. P. and Gettelman, A.: Impact of Antarctic mixed-phase clouds on climate, P. Natl. Acad. Sci. USA, 111, 18156-18161, https://doi.org/10.1073/pnas.1418197111, 2014.

Lim, K.-S. S. and Hong, S.-Y.: Development of an Effective Double-Moment Cloud Microphysics Scheme with Prognostic Cloud Condensation Nuclei (CCN) for Weather and Climate Models, Mon. Weather Rev., 138, 1587-1612, https://doi.org/10.1175/2009mwr2968.1, 2010.

Lubin, D., Chen, B., Bromwich, D. H., Somerville, R. C. J., Lee, W.-H., and Hines, K. M.: The Impact of Antarctic Cloud Radiative Properties on a GCM Climate Simulation, J. Climate, 11, 447-462, https://doi.org/10.1175/15200442(1998)011<0447:TIOACR>2.0.CO;2, 1998.

Meyers, M. P., Demott, P. J., and Cotton, W. R.: New Primary Ice-Nucleation Parameterizations in an Explicit Cloud Model, J. Appl. Meteorol., 31, 708-721, https://doi.org/10.1175/15200450(1992)031<0708:NPINPI>2.0.CO;2, 1992.

Milbrandt, J. A. and Yau, M. K.: A Multimoment Bulk Microphysics Parameterization. Part I: Analysis of the Role of the Spectral Shape Parameter, J. Atmos. Sci., 62, 3051-3064, https://doi.org/10.1175/JAS3534.1, 2005a.

Milbrandt, J. A. and Yau, M. K.: A Multimoment Bulk Microphysics Parameterization. Part II: A Proposed Three-Moment Closure and Scheme Description, J. Atmos. Sci., 62, 3065-3081, https://doi.org/10.1175/JAS3535.1, 2005b.

Morris, E. M. and Vaughan, D. G.: Spatial and temporal variation of surface temperature on the Antarctic Peninsula and the limit of viability of ice shelves, in: Antarctic Peninsula Climate Variability: Historical and Paleoenvironmental Perspectives, WileyBlackwell, 61-68, https://doi.org/10.1029/ar079p0061, 2003.

Morrison, H., Curry, J. A., and Khvorostyanov, V. I.: A New Double-Moment Microphysics Parameterization for Application in Cloud and Climate Models. Part I: Description, J. Atmos. Sci., 62, 1665-1677, https://doi.org/10.1175/jas3446.1, 2005.

Morrison, H., Thompson, G., and Tatarskii, V.: Impact of Cloud Microphysics on the Development of Trailing Stratiform Precipitation in a Simulated Squall Line: Comparison of One- and Two-Moment Schemes, Mon. Weather Rev., 137, 991-1007, https://doi.org/10.1175/2008MWR2556.1, 2009.

O’Donnell, R., Lewis, N., McIntyre, S., and Condon, J.: Improved Methods for PCA-Based Reconstructions: Case Study Using the Steig et al. (2009) Antarctic Temperature Reconstruction, J. Climate, 24, 2099-2115, https://doi.org/10.1175/2010JCLI3656.1, 2011.

O'Shea, S. J., Choularton, T. W., Flynn, M., Bower, K. N., Gallagher, M., Crosier, J., Crawford, I., Fleming, Z., Listowski, C., Kirchgaessner, A., Ladkin, R. S., and Lachlan-Cope, T.: In situ measurements of cloud microphysics and aerosol over coastal Antarctica during the MAC campaign, Atmos. Chem. Phys. Discuss., https://doi.org/10.5194/acp-2017-212, in review, 2017.

Peckham, S., Grell, G. A., McKeen, S. A., Barth, M., Pfister, G., Wiedinmyera, C., Fast, J. D., Gustafson, W. I., Zaveri, R., Easter, R. C., Barnard, J., Chapman, E., Hewson, M., Schmitz, R., Salzmann, M., and Freitas, S.: 2011: WRF-Chem Version 3.3 User's Guide. NOAA Technical Memo., Boulder, Colorado, USA, 98 pp., 2011.

Powers, J. G., Manning, K. W., Bromwich, D. H., Cassano, J. J., and Cayette, A. M.: A Decade of Antarctic Science Support Through Amps, B. Am. Meteorol. Soc., 93, 1699-1712, https://doi.org/10.1175/bams-d-11-00186.1, 2012.

Reisner, J., Rasmussen, R. M., and Bruintjes, R. T.: Explicit forecasting of supercooled liquid water in winter storms using the MM5 mesoscale model, Q. J. Roy. Meteor. Soc., 124, 10711107, https://doi.org/10.1002/qj.49712454804, 1998.

Skamarock, W. C., Klemp, J. B., Dudhia, J., Gill, D. O., Barker, D. M., Huang, X.-Y., Wang, W., and Powers, J. G.: A Description of the Advanced Research WRF Version 3, NCAR Tech. Note, NCAR/TN-475 + STR, 125 pp., Natl. Cent. for Atmos. Res, Boulder, Colorado, USA, 2008.

Stickney, T. M., Shedlov, M. W., and Thompsoni, D. I.: Goodrich total temperature sensors. Technical report 5755, Tech. rep., Goodrich Corporation, Burnsville, MN, USA, 1994.

Thompson, G., Field, P. R., Rasmussen, R. M., and Hall, W. D.: Explicit Forecasts of Winter Precipitation Using an Improved Bulk Microphysics Scheme. Part II: Implementation of a New Snow Parameterization, Mon. Weather Rev., 136, 5095, https://doi.org/10.1175/2008MWR2387.1, 2008.

Turner, J., Lu, H., White, I., King, J. C., Phillips, T., Hosking, J. S., Bracegirdle, T. J., Marshall, G. J., Mulvaney, R., and Deb, P.: Absence of 21st century warming on Antarctic Peninsula consistent with natural variability, Nature, 535, 411-415, https://doi.org/10.1038/nature18645, 2016.

van Wessem, J. M., Reijmer, C. H., Lenaerts, J. T. M., van de Berg, W. J., van den Broeke, M. R., and van Meijgaard, E.: Updated cloud physics in a regional atmospheric climate model improves the modelled surface energy balance of Antarctica, The 
Cryosphere, 8, 125-135, https://doi.org/10.5194/tc-8-125-2014, 2014.

Wesslén, C., Tjernström, M., Bromwich, D. H., de Boer, G., Ekman, A. M. L., Bai, L.-S., and Wang, S.-H.: The Arctic summer atmosphere: an evaluation of reanalyses using ASCOS data, Atmos. Chem. Phys., 14, 2605-2624, https://doi.org/10.5194/acp14-2605-2014, 2014.

Wilson, D. R. and Ballard, S. P.: A microphysically based precipitation scheme for the UK meteorological office unified model, Q. J. Roy. Meteor. Soc., 125, 1607-1636, https://doi.org/10.1002/qj.49712555707, 1999.
Wouters, B., Martin-Español, A., Helm, V., Flament, T., van Wessem, J. M., Ligtenberg, S. R. M., van den Broeke, M. R., and Bamber, J. L.: Dynamic thinning of glaciers on the Southern Antarctic Peninsula, Science, 348, 899-903, https://doi.org/10.1126/science.aaa5727, 2015.

Yang, X., Pyle, J. A., and Cox, R. A.: Sea salt aerosol production and bromine release: Role of snow on sea ice, Geophys. Res. Lett., 35, L16815, https://doi.org/10.1029/2008g1034536, 2008. 